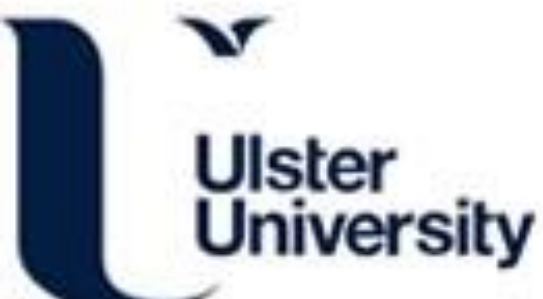

\section{Production of reduced graphene oxide via hydrothermal reduction in an aqueous sulphuric acid suspension and its electrochemical behaviour}

Hayes, WI., Joseph, P., Mughal, MZ., \& Papakonstantinou, P. (2015). Production of reduced graphene oxide via hydrothermal reduction in an aqueous sulphuric acid suspension and its electrochemical behaviour. Journal of Solid State Electrochemistry, 19, 361-380. https://doi.org/10.1007/s10008-014-2560-6

Link to publication record in Ulster University Research Portal

Published in:

Journal of Solid State Electrochemistry

Publication Status:

Published (in print/issue): 01/01/2015

DOI:

$10.1007 / \mathrm{s} 10008-014-2560-6$

Document Version

Publisher's PDF, also known as Version of record

\section{General rights}

Copyright for the publications made accessible via Ulster University's Research Portal is retained by the author(s) and / or other copyright owners and it is a condition of accessing these publications that users recognise and abide by the legal requirements associated with these rights.

\section{Take down policy}

The Research Portal is Ulster University's institutional repository that provides access to Ulster's research outputs. Every effort has been made to ensure that content in the Research Portal does not infringe any person's rights, or applicable UK laws. If you discover content in the Research Portal that you believe breaches copyright or violates any law, please contact pure-support@ulster.ac.uk. 


\title{
Production of reduced graphene oxide via hydrothermal reduction in an aqueous sulphuric acid suspension and its electrochemical behaviour
}

\author{
William Ignatius Hayes • Paul Joseph • \\ Muhammad Zeeshan Mughal • \\ Pagona Papakonstantinou
}

Received: 14 May 2014 / Revised: 21 June 2014 / Accepted: 24 June 2014

(C) Springer-Verlag Berlin Heidelberg 2014

\begin{abstract}
Widespread availability of fuel cells is being delayed due to the scarcity and high expense of precious metal catalysts, which presently provide the most efficient oxygen reduction reaction (ORR). Research has shown efficient electrocatalysis towards ORR from carbon materials offers a possible alternative to precious metal catalysts. Increasing focus is being given to the provision of graphene by the reduction of graphene oxide (GO) as a facile method for possible up-scaled production. Presented is a novel method for the production of electrocatalytic graphene-like material, involving the hydrothermal reduction of $\mathrm{GO}$ suspended in $0.1 \mathrm{M}$ sulphuric acid (denoted as $\mathrm{rGO}_{2} \mathrm{SO}_{4}$ ). The $\mathrm{rGO}$ $\mathrm{H}_{2} \mathrm{SO}_{4}$ sample provides a more efficient electron transfer during ORR than GO reduction in hydrazine (denoted as rGO $\mathrm{N}_{2} \mathrm{H}_{4}$ ), a commonly employed, but toxic reducing agent. The overall current observed from the $\mathrm{rGO}_{2} \mathrm{SO}_{4}$ preparation is similar to that provided by $\mathrm{rGO} \mathrm{N}_{2} \mathrm{H}_{4}$ during diffusioncontrolled linear sweep voltammetry analysis. Oxygen reduction catalysis of the $\mathrm{rGO}_{2} \mathrm{SO}_{4}$ sample is seen to be promoted by the incorporation of sulphur, along with the high level of surface defects created after GO reduction. The diffusiondependent conditions of cyclic voltammetry analysis confirms a pseudocapacitive response from the rGO preparations. The stability of this pseudocapacitance is significant for all
\end{abstract}

Electronic supplementary material The online version of this article (doi:10.1007/s10008-014-2560-6) contains supplementary material, which is available to authorized users.

W. I. Hayes $(\triangle) \cdot$ M. Z. Mughal $\cdot$ P. Papakonstantinou

School of Engineering, University of Ulster at Jordanstown, Shore

Road, Newtownabbey, BT37 0QB Northern Ireland, UK

e-mail: liamhayes6@hotmail.com

P. Joseph

School of the Built Environment, University of Ulster at Jordanstown, Shore Road, Newtownabbey, BT37 0QB Northern Ireland, UK reduced graphene oxide (rGO) samples discussed, opening the possible dual application of both electrical power generation and power storage capabilities.

Keywords Reduced graphene oxide $\cdot$ Hydrothermal reduction - Oxygen reduction reaction - Pseudocapacitance . Alkaline fuel cell $\cdot$ Supercapacitor

\section{Introduction}

The production of graphite oxide from graphite has been possible for the last 150 years [1]. Hummer's method produces graphite oxide that is susceptible to the intercalation of aqueous solutions [2] causing the carbon lattice layers to expand. The carbon atoms bound to an epoxy or a hydroxyl group mostly are the sites of defective $s p^{3}$ carbon formation after oxidation [3], inferring an interruption of the carbon lattice $s p^{2}$ structure $[4,5]$. The fraction of $s p^{2}$ carbon in fully oxidised graphene oxide is $\sim 0.80$ [6], with $\sim 38 \%$ of carbon atoms in a $\mathrm{GO}$ preparation consisting of $\mathrm{C}-\mathrm{O}$ bonds of epoxy and hydroxyl groups at the basal plane [6]. After GO reduction, the oxygen content dramatically decreases $[3,6,7]$, together with an increase in conductivity [8-10]. Some of the most common chemicals used for reduction of graphene oxide have been sodium borohydride and hydrazine [9, 11-13]. Graphene oxide reduced by hydrazine has a higher resistance than graphene produced via other chemically based methods, such as sodium borohydride [9, 14]. Hydrazine is a potent antioxidant which effectively scavenges the abundant oxygen functional groups present at the surface of carbon lattices [15].

The main types of reduction process employed in reducing graphene oxide involve thermal or chemical treatment. Chemical processing does not presently allow the level of GO reduction to be easily controlled. Synergistic application of 
multiple chemical reductants, such as sodium borohydride $\left(\mathrm{NaBH}_{4}\right)$ and hydroquinone [16], can aid in the enhanced delivery of functionalised graphitic material from reducing GO. The mechanism of hydroquinone reduction of graphene oxide is suggested to be because of the loss of one $\mathrm{H}^{+}$ion providing monophenolate or two $\mathrm{H}^{+}$ions resulting in a diphenolate ion $[15,17]$. However, the toxic nature of hydrazine and sodium borohydride could render a high disposal cost during industrial delivery of reduced graphene oxide. Methods of thermal GO reduction are continually being evaluated to expedite the route to an effective mass production method for graphene [18-22]. Thermal reduction of GO has been obtained by varying the ambient gas (argon, hydrogen, nitrogen, ammonia, ultra-high vacuum) or through a variation in the heating source $[3,18,22-29]$. The degree of GO reduction can be adjusted by varying the heating temperature and treatment duration. Exfoliation by thermal expansion of GO to deliver functionalised graphene sheets is dependent on the decomposition rate of the oxygen groups [30]. When the decomposition rate of the epoxy and hydroxyl groups exceeds the diffusion rate of the gases released from the thermal reduction treatment, a positive pressure is exerted between the carbon lattice layers. When this pressure exerts a stronger force than the van der Waals forces binding the stacked carbon lattice layers, exfoliation occurs, providing few to single layer functionalised graphene [30]. The main drawback of thermally reduced GO is the high energy requirements, which inhibit up-scaling of a GO reduction process to an industrial level.

Hydrothermal reduction is a process whereby the thermal treatment of GO is completed at high pressure within a sealed vessel. The $\mathrm{pH}$ and temperature of a GO suspension influences structure and behaviour of the final rGO product [31-33]. Other work has included the application of sulphuric acid to assist the reduction of $\mathrm{GO}$ by $\mathrm{NaBH}_{4}$ [34]. The addition of sulphuric acid into GO solvent suspensions $(N, N$ '-dimethylformamide (DMF), dimethyl sulfoxide (DMSO)) has inferred significant electrochemical enhancement of the resultant rGO product produced at room pressure [35]. The reduction of $\mathrm{GO}$ by pure sulphur is due to a reaction with hydrogen sulphide $\left(\mathrm{H}_{2} \mathrm{~S}\right)$ and sulphurous acid $\left(\mathrm{H}_{2} \mathrm{SO}_{3}\right)$, which are reducing agents found from a sulphur solution [36]. Complete GO reduction by pure sulphur is difficult to achieve [36]. GO reduction has resulted in graphene that is particularly effective towards energy storage, facilitated by a high supercapacitive behaviour [37]. Developments have also highlighted the effectiveness of $\mathrm{rGO}$ as an electrocatalyst for ORR $[36,38]$. The reduction of GO by hydrazine is observed to cause the incorporation of nitrogen into the graphene lattice structure, along with a decrease in the oxygen functional groups, which assist in promotion of electrocatalysis [11, 39]. The presence of nitrogen results from the formation of hydrazides and hydrazones, which in turn are derived during the interaction of hydrazine with lactones, anhydrides and quinone derivatives present at the graphene oxide surface [15].

The thermal reduction of GO can successfully deliver single graphene sheets [3], but a minimum temperature requirement is estimated to be above $550{ }^{\circ} \mathrm{C}$ at room pressure [30]. GO reduction in the present study is completed in aqueous solution, as the hydrophilicity of GO allows a high degree of solution intercalation between the carbon lattice layers. This facilitates a high contact surface area during rGO production [36, 40]. Also, the temperature is kept relatively low during hydrothermal treatment, assisting in the energy efficient provision of graphene. The novelty of this study lies in the application of an aqueous sulphuric acid solution during hydrothermal treatment, providing $\mathrm{rGO}$ which exhibits significant ORR catalysis.

\section{Experimental}

\section{Graphene oxide production}

Graphene oxide was prepared via a modified Hummer's method [41-43]. Briefly, mixing of graphite (2.5 g) was done with sodium nitrate $\left(\mathrm{NaNO}_{3}\right)(2 \mathrm{~g})$, concentrated sulphuric acid $(70 \mathrm{ml})$ and potassium permanganate $\left(\mathrm{KMnO}_{4}\right)(10 \mathrm{~g})$. The resultant mixture was heated to $50^{\circ} \mathrm{C}$ for 6 hours, followed by overnight cooling and further subsequent heating to $35^{\circ} \mathrm{C}$. After cooling, a further portion of $\mathrm{KMnO}_{4}(10 \mathrm{~g})$ was added and the reaction mixture was heated to $35^{\circ} \mathrm{C}$ overnight. This solution was then cooled to room temperature allowing the safe addition of hydrogen peroxide $\left(\mathrm{H}_{2} \mathrm{O}_{2}\right)(3 \mathrm{ml}$ of 30 wt.\%). Settling for 5 days assured cessation of the reduction reaction. The reaction sludge was isolated via centrifugation (3,000 rpm for 30 minutes) and re-suspended a further four times in 3 wt.\% sulphuric acid and 0.5 wt.\% hydrogen peroxide. The isolated GO sludge was suspended in distilled water repeatedly until $\mathrm{pH} \sim 3$ was obtained. The resultant product was then suspended in distilled water $\left(1 \mathrm{mg} \mathrm{ml}^{-1}\right)$ and sonicated for 5 hours to ensure sufficient exfoliation to graphene oxide. Afterwards, the GO solution was centrifuged at $3,000 \mathrm{rpm}$ for 30 minutes to isolate the graphene oxide particulates. The supernatant was decanted after centrifugation, allowing the graphene oxide to remain as a moist particulate sludge. This graphene oxide sludge was then freeze-dried to facilitate drying, while preventing coagulation of the particles. The freeze-dried graphene oxide powder was then used for assessment of the proposed hydrothermal reduction processes.

\section{Reduction of graphene oxide}

Reduction of freeze-dried GO was carried out at $190{ }^{\circ} \mathrm{C}$ for $12 \mathrm{~h}$ at high pressure in an air-tight general purpose pressure vessel (Parr Instruments, USA; Part No. 
236HC10TCT316121402; Serial No. 26905). The hot plate assembly controls the temperature of the internal hydrothermal chamber via an in -situ thermostat. All GO suspensions were sonicated for 30 minutes and then placed in a Teflon container and covered with a Teflon lid. The Teflon container was then placed in the pressure vessel to reduce the GO at high pressure. The reduction suspensions were prepared with $2 \mathrm{mg} \mathrm{ml}^{-1}$ of GO in distilled water with a pH 3.8 (denoted as $\mathrm{rGO}$ DI $\mathrm{H}_{2} \mathrm{O}$ ) and $0.1 \mathrm{M}$ sulphuric acid with a $\mathrm{pH} 1.16$ (denoted as $\mathrm{rGO} \mathrm{H}_{2} \mathrm{SO}_{4}$ ), respectively, at high pressure $(180 \mathrm{psi})$. An additional reduction was carried out in the presence of hydrazine and was used as a positive control to facilitate comparison to a known effective reduction treatment. For this control sample, GO $\left(1 \mathrm{mg} \mathrm{ml}^{-1}\right)$ was suspended in $0.33 \mathrm{M}$ hydrazine aqueous solution and heated in the pressure vessel $(190 \mathrm{psi})$ at $190{ }^{\circ} \mathrm{C}$ for 12 hours (denoted as rGO $\mathrm{N}_{2} \mathrm{H}_{4}$ ). After hydrothermal reduction in the required medium, cleaning of the rGO powder was carried out. A typical cleaning procedure involved the sonication of the rGO suspension after hydrothermal treatment for 5 minutes. This was then centrifuged for 30 minutes at 3,000 rpm. The supernatant was decanted, and the rGO pellet was suspended in ethanol. The sample was sonicated and suspended as previously mentioned. This re-suspension in ethanol was followed by three repetitive sonication cycles. The rGO was then dried over night at $40{ }^{\circ} \mathrm{C}$.

\section{Catalyst coating preparation}

Catalyst inks were prepared by adding catalyst powder $(5 \mathrm{mg})$ to a 1:20 dilution of Nafion 117 in DMF (1 ml). Homogeneity was assured via sonication for 15 minutes. Pipetting was used to prepare a $0.424 \mathrm{mg} \mathrm{cm}^{-2}$ coating of rGO on a glassy carbon (GC) rotating disc electrode (RDE) tip (BASi Analytical; 3$\mathrm{mm}$ diameter disc). Measurements of platinum nominally $20 \%$ on carbon black $(\mathrm{Pt} / \mathrm{C})$ were carried out on a $0.283 \mathrm{mg} \mathrm{cm}^{-2}$ coating, also drop-dried onto a glassy carbon electrode (GCE) disc to allow comparison to a known and successful ORR catalyst. The deposited catalyst ink was gradually dried under an infrared (IR) lamp, forming a sufficiently adhered catalyst coating to the GCE disc.

\section{Electrochemical characterisation}

All electrochemical analysis was recorded on a softwarecontrolled Autolab PGSTAT20 potentiostat/galvanostat system (Eco-Chemie, The Netherlands). The measurement cell comprised of a GCE RDE tip as a working electrode with a silver/silver chloride $(\mathrm{Ag} / \mathrm{AgCl})$ reference electrode and platinum $(\mathrm{Pt})$ wire as a counter electrode. Voltammograms were captured within +0.2 to $-1.0 \mathrm{~V}$ in $0.1 \mathrm{M}$ potassium hydroxide $(\mathrm{KOH})$ with flow of an individual dissolved gas $\left(\mathrm{O}_{2}\right.$ or $\left.\mathrm{N}_{2}\right)$ into the $0.1 \mathrm{M} \mathrm{KOH}$ electrolyte providing saturation as necessary. Linear sweep voltammetry (LSV) was carried out at $1,600 \mathrm{rpm}$ with a $10 \mathrm{mV} \mathrm{s}^{-1}$ scan rate. The KouteckyLevich (K-L) equation was used to calculate ORR kinetic efficiency from LSV scans taken from 225 to $3,600 \mathrm{rpm}$. Throughout the voltammetric results discussed in this paper, the current response is displayed with respect to the current $(\mathrm{mA})$ provided per gram $(\mathrm{g})$ of catalyst coating, which allows a closer comparison to previously published studies. Chronoamperometric measurements were recorded in $\mathrm{O}_{2}$-saturated $0.1 \mathrm{M} \mathrm{KOH}$ with a GCE rotation of 1,600 rpm using an applied potential taken from the LSV scan of the catalyst powder in question. Electrochemical impedance spectroscopy (EIS) was captured at a fixed potential of $-0.1 \mathrm{~V}$ for all measurements. A superimposed alternating potential with a $10 \mathrm{mV}$ amplitude was also applied at a frequency of $10^{6}$ to $10^{-2} \mathrm{~Hz}$ in a single sine mode using $\mathrm{O}_{2}$-saturated $0.1 \mathrm{M} \mathrm{KOH}$ electrolyte under convection-controlled conditions.

\section{Material characterisation}

X-ray diffractometry (XRD) was carried out on a Bruker D8Discover diffractometer. Measurement parameters consisted of an increment of $0.04^{\circ}$ of the $2 \theta$ angle with a 10 -s hold time. The $2 \theta$ angle range of operation was $3^{\circ}-70^{\circ}$. Tapping mode atomic force microscopy (AFM) analysis was completed with a scanning probe Veeco Dimension 3100 microscope using TESP levers (nominal stiffness $\sim 40 \mathrm{~N} \mathrm{~m}^{-1}$ ) operated slightly below resonance $(300 \mathrm{kHz})$. A Labram system using a $\mathrm{He}-\mathrm{Ne}$ laser $(\lambda 632.81 \mathrm{~nm})$ was used to generate Raman spectra data. $\mathrm{X}$-ray photoelectron spectroscopy (XPS) analysis was carried out on a Kratos Axis Ultra DLD spectrometer. Scanning electron microscopy (SEM) imaging was carried out using a FEI Quanta 300D system. A multi-point Brunauer-EmmettTeller (BET) method was employed for this study. The linear plot required for BET surface area calculations is taken from the $\mathcal{P}_{0} / \mathcal{P}$ range of $0.05-0.35$ in the $\mathrm{N}_{2}$ adsorption scan. Nitrogen gas adsorption and desorption behaviour was analysed with a Autosorb-1 system manufactured by Quantachrome Instruments, Boynton Beach, FL, USA.

\section{Results and discussion}

Surface topography of graphene oxide reduced in various hydrothermal media

SEM images of the graphene oxide and rGO samples show the largest particles present within the whole powder preparation (Fig. 1). A highly roughened surface for the GO and rGO samples [30] is due to the freeze-drying treatment and is in contrast to the smoother surface of the graphite raw material and the oven-dried GO (Fig. 1). 

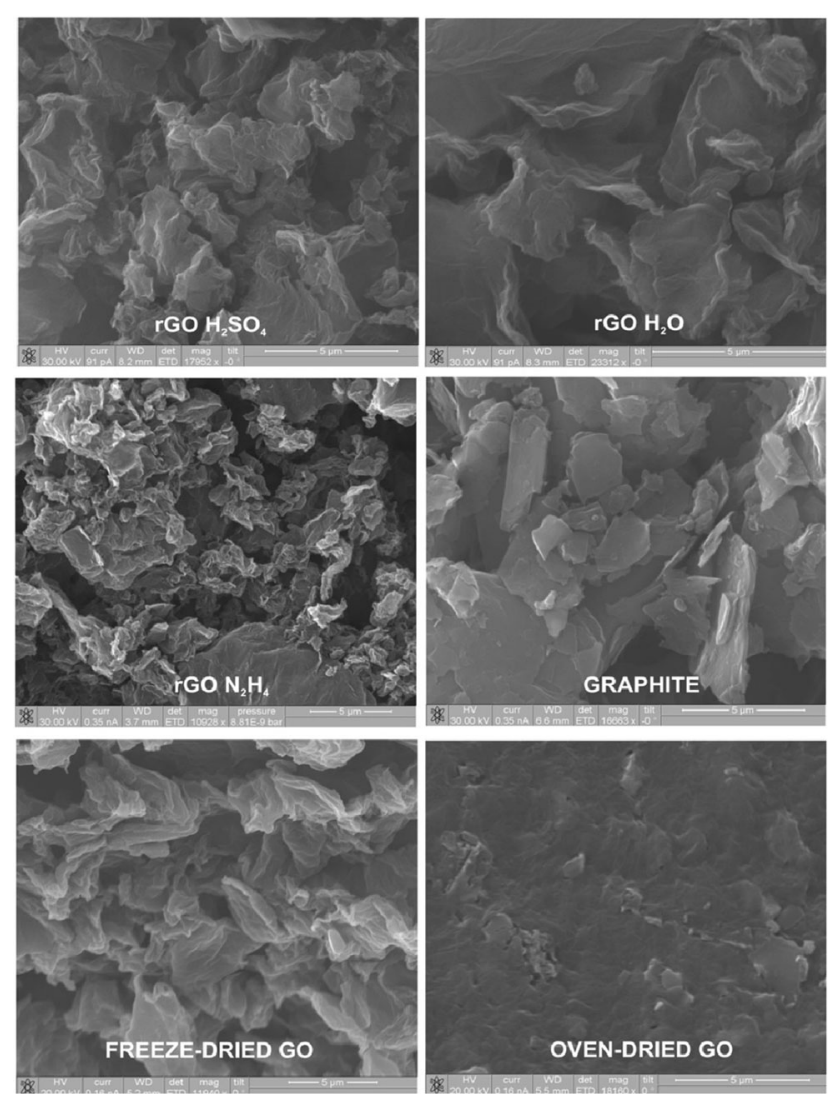

Fig. 1 SEM images of freeze-dried graphene oxide versus oven-dried graphene oxide, graphite and graphene oxide reduced at $190{ }^{\circ} \mathrm{C}$ under high pressure (180-190 psi) for 12 hours in distilled water $\left(\mathrm{rGO} \mathrm{DI} \mathrm{H}_{2} \mathrm{O}\right)$, $0.1 \mathrm{M}$ sulphuric acid $\left(\mathrm{rGO} \mathrm{H}_{2} \mathrm{SO}_{4}\right)$ and $0.33 \mathrm{M}$ hydrazine $\left(\mathrm{rGO} \mathrm{N}_{2} \mathrm{H}_{4}\right)$. Freeze-dried graphene oxide was employed in the provision of all $\mathrm{rGO}$ samples

A highly distorted surface and topography can prevent face-to-face stacking of the graphene layers, while also enhancing the formation of mesopores and macropores, which bestow significant capacitive behaviour [44, 45]. The presence of a porous surface after GO reduction would also attribute a considerable electrostatic capacitance to the surface of the rGO particles.

Examination of the surface structure of graphene oxide after hydrothermal reduction in varied media

Raman analysis of GO, graphite and rGO samples displayed in Fig. 2 shows positioning of the diamondoid (D), graphitic (G) and 2-D peaks that are typical for graphitic-based materials [6, 46, 47]. It is appropriate to consider the Raman data separately to obtain more complete information on the structure of the rGO samples investigated (Figs. 2 and S1). The 2-D peak present at $\sim 2,700 \mathrm{~cm}^{-1}$ is activated by the $A_{1}{ }^{\prime}$ phonon but is depressed in a highly disordered structure (Figs. 2 and S1) $[48,49]$. A well-defined 2-D peak exists in a highly ordered crystalline structure, such as what is found in the carbon lattice
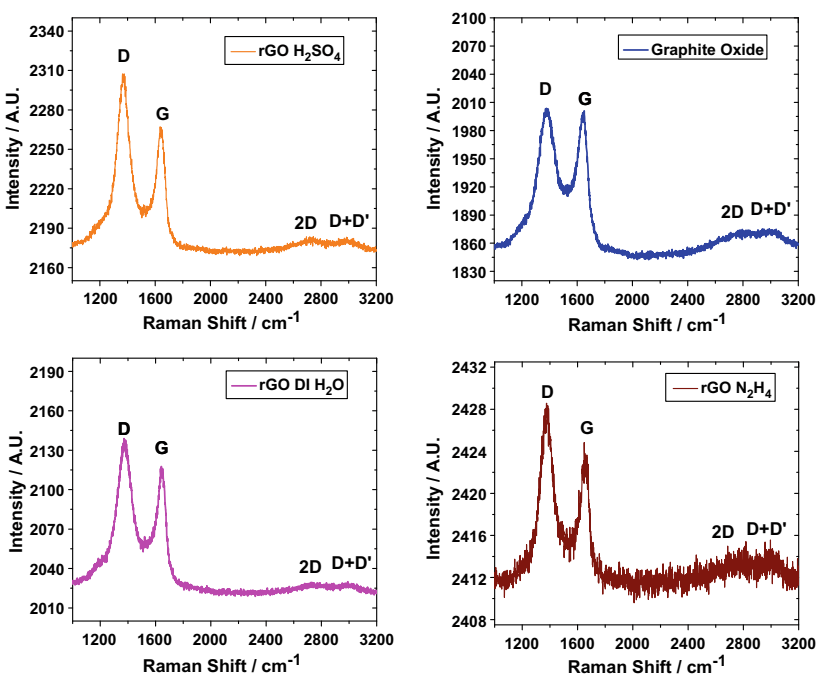

Fig. 2 Raman spectra of graphite oxide before exfoliation and graphene oxide reduced hydrothermally $\left(190{ }^{\circ} \mathrm{C}\right.$ for 12 hours at high pressure (180-190 psi)) in distilled water $\left(\mathrm{rGO}\right.$ DI $\left.\mathrm{H}_{2} \mathrm{O}\right), 0.1 \mathrm{M}$ sulphuric acid $\left(\mathrm{rGO} \mathrm{H}_{2} \mathrm{SO}_{4}\right)$ and $0.33 \mathrm{M}$ hydrazine $\left(\mathrm{rGO} \mathrm{N}_{2} \mathrm{H}_{4}\right)$, respectively

layers of graphene $[50,51]$. The rGO samples and GO displayed in Figs. 2 of this manuscript and S1 of the supporting information have a highly disrupted graphitic structure, indicated by a prominent D-peak, most likely caused by the incorporation of a high amount of oxygen. The D-peak is stimulated at $\sim 1,360 \mathrm{~cm}^{-1}$ by the $A_{1} g$ phonon and can be caused by the presence of structural defects within the material [52]. These defects become notably heightened in intensity after the oxidation of graphite to $\mathrm{GO}$ and can persist to a significant degree in the subsequent $\mathrm{rGO}$ samples after GO reduction. The G-peak is present at $\sim 1,580 \mathrm{~cm}^{-1}$, being stimulated by the $E_{2} g$ phonon vibrations of the $s p^{2}$ carbon hybridisation [53]. The $\mathrm{D}+\mathrm{D}^{\prime}$ peak present at $2,940 \mathrm{~cm}^{-1}$ shows the combined effect of phonons which vibrate at different frequencies; these vibrations are influenced by the presence of structural defects [54].

An overall decrease in the in-plane $s p^{2}$ domain size is seen to occur after oxidation and exfoliation of graphite. This is suggested by Raman analysis data, as an increase in the $I_{D} / I_{G}$ ratio from 0.32 for graphite to 1.01 for graphite oxide and 1.12 for graphene oxide (Table 1) [35, 55]. A further decrease in the $s p^{2}$ domain size after hydrothermal reduction of graphene oxide is indicated with an increase in the $I_{D} / I_{G}$ ratio, which also indicates an increase in the surface defects as a result of the abrasive removal of oxygen functional groups (Table 1) [7, 55-57]. Sulphur incorporated into the $\mathrm{rGO} \mathrm{H}_{2} \mathrm{SO}_{4}$ sample (Figs. 6 and 7; Table 4) may contribute to the increased level of defects [58], which is indicated by the high $I_{D} / I_{G}$ ratio (1.43) for this sample (Table 1).

Table 1 shows that defects are lowest in the rGO derived from hydrazine reduction ( $\mathrm{pH}$ of hydrothermal suspension for rGO $\mathrm{N}_{2} \mathrm{H}_{4}=\sim 10 ; I_{D} / I_{G}=1.00$ ), while a higher level is 
Table 1 Raman spectra data showing the change observed in the D-peak intensity in relation to the G-peak intensity $\left(I_{D} / I_{G}\right)$ of graphite, graphite oxide, graphene oxide and graphene oxide reduced in distilled water $\left(\mathrm{rGO}\right.$ DI H $\left.\mathrm{H}_{2} \mathrm{O}\right), 0.1 \mathrm{M}$ sulphuric acid $\left(\mathrm{rGO} \mathrm{H}_{2} \mathrm{SO}_{4}\right)$ and $0.33 \mathrm{M}$ hydrazine $\left(\mathrm{rGO} \mathrm{N}{ }_{2} \mathrm{H}_{4}\right)$, respectively

\begin{tabular}{ll}
\hline Sample name & $I_{D} / I_{G}$ ratio \\
\hline Graphite & 0.32 \\
Graphite oxide & 1.01 \\
Graphene oxide & 1.12 \\
rGO DI H$H_{2} \mathrm{O}$ & 1.21 \\
rGO $\mathrm{H}_{2} \mathrm{SO}_{4}$ & 1.43 \\
$\mathrm{rGO} \mathrm{N} \mathrm{H}_{4}$ & 1.00 \\
\hline
\end{tabular}

observed in the $\mathrm{rGO} \mathrm{H}_{2} \mathrm{SO}_{4}$ sample ( $\mathrm{pH}$ of hydrothermal suspension for $\mathrm{rGO} \mathrm{H}_{2} \mathrm{SO}_{4}=\mathrm{pH} \sim 1 ; I_{D} / I_{G}=1.43$ ). This correlates with previous work [32], which shows that the more acidic the graphene oxide suspension during hydrothermal reduction, the higher the level of defects at the surface of the rGO samples. The rGO DI $\mathrm{H}_{2} \mathrm{O}\left(I_{D} / I_{G}=\right.$ 1.21) sample has a lower $I_{D} / I_{G}$ value than $\mathrm{rGO} \mathrm{H}_{2} \mathrm{SO}_{4}\left(I_{D} /\right.$ $I_{G}=1.43$ ), showing defects are lower in the rGO DI $\mathrm{H}_{2} \mathrm{O}$ sample. Hydrazine has been previously reported to provide little to no change in the $I_{D} / I_{G}$ ratio of GO after reduction [55]. This is also seen to occur in the current study with graphene oxide providing an $I_{D} / I_{G}$ ratio of 1.01 , while after reduction in $0.33 \mathrm{M}$ hydrazine, the $I_{D} /$ $I_{G}$ ratio is nearly unchanged at 1.00 .
Effect on carbon lattice spacing from rGO production in varied hydrothermal media

XRD analysis confirms the reduction of GO after hydrothermal treatment in the varying media considered during this study, indicated by the shift in position of the carbon 002 peak. Shown in Fig. 3 is a change in the interlayer spacing of the carbon lattices after graphene oxide reduction. In graphene oxide, the carbon 002 peak is present at $2 \theta=11.8^{\circ}$ [59]. All of the rGO samples have a 002 peak of $2 \theta=\sim 25^{\circ}$, similar to the starting graphite material, with a 002 carbon peak at $26.48^{\circ}$. This indicates a close to complete restoration of the aromatic carbon $s p^{2}$ lattice spacing in all reduced graphene oxide samples.

The interlayer spacing of the graphene sheets from the rGO DI $\mathrm{H}_{2} \mathrm{O}$ and $\mathrm{rGO}_{2} \mathrm{SO}_{4}$ samples is indicated to be 3.63 and $3.65 \AA$, respectively (Table 2). This decrease in the lattice spacing after reduction of graphene oxide is caused by the removal of the oxygen-containing functional groups bound to the surface of the graphene lattice layers [60].

During the oxidation of graphite, the increase in the interlattice spacing can be assisted by water being trapped between carbon lattice layers in an aqueous suspension, as the surface of the inter-layer spacing is hydrophilic [61, 62]. An increase in the temperature of the GO suspension evaporates the water between the carbon lattice layers, causing the spacing to expand. After hydrothermal reduction of GO, the deoxygenation results in the rGO becoming more hydrophobic, expelling residual water molecules from the interlayer cavity. This facilitates a decrease in the inter-layer spacing of the graphene oxide
Fig. 3 Powder XRD spectra showing the change in the intensity of the angle of X-ray reflection from the surface of graphene oxide reduced in distilled water ( $\mathrm{rGO}$ DI $\mathrm{H}_{2} \mathrm{O}$ ), $0.33 \mathrm{M}$ hydrazine $\left(\mathrm{rGO} \mathrm{N} \mathrm{H}_{4}\right)$ and $0.1 \mathrm{M}$ sulphuric acid (rGO $\mathrm{H}_{2} \mathrm{SO}_{4}$ ), respectively. A comparison to the graphene oxide before reduction and the untreated graphite are also displayed
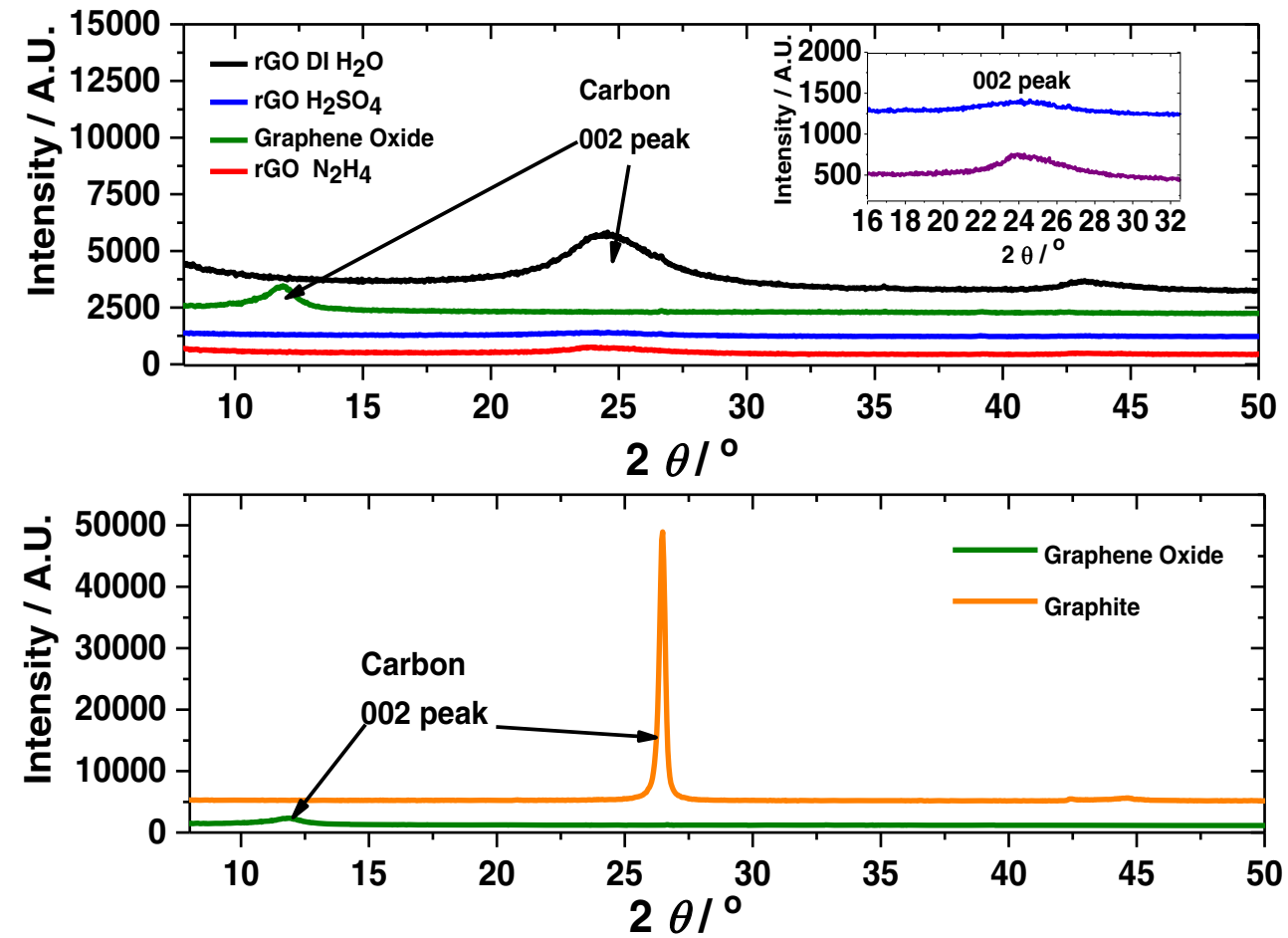
Table 2 Change in the carbon lattice spacing ( $d$-spacing) between the carbon lattice layers of graphene oxide, untreated graphite and graphene oxide reduced in distilled water $\left(\mathrm{rGO} \mathrm{DI} \mathrm{H}_{2} \mathrm{O}\right), 0.1 \mathrm{M}$ sulphuric acid $\left(\mathrm{rGO} \mathrm{H}_{2} \mathrm{SO}_{4}\right)$ and $0.33 \mathrm{M}$ hydrazine $\left(\mathrm{rGO} \mathrm{N}_{2} \mathrm{H}_{4}\right)$, respectively

\begin{tabular}{ll}
\hline Sample name & Carbon lattice spacing $(\AA)$ \\
\hline Graphene oxide & 7.46 \\
Graphite & 3.36 \\
rGO DI H$~_{2} \mathrm{O}$ & 3.63 \\
$\mathrm{rGO} \mathrm{H} \mathrm{SO}_{4}$ & 3.65 \\
$\mathrm{rGO} \mathrm{N} \mathrm{H}_{4}$ & 3.72 \\
\hline
\end{tabular}

Determined from XRD analysis data displayed in Fig. 3

after reduction together with the removal of oxygen-containing functional groups [61]. There is a slightly larger inter-lattice spacing observed between the carbon layers of the rGO samples (3.63 $\AA-3.72 \AA)$ of this study in comparison to the graphite raw material (3.36 $\AA$ ). Persistence of a significant portion of oxygen-based functional groups after $\mathrm{GO}$ reduction $(\mathrm{O} 1 \mathrm{~s} \mathrm{rGO}$ $\mathrm{N}_{2} \mathrm{H}_{4}=5.12$ at.\%, rGO DI $\mathrm{H}_{2} \mathrm{O}=14.47$ at.\%, rGO $\mathrm{H}_{2} \mathrm{SO}_{4}=$ 16.09 at.\%) would promote a higher carbon lattice spacing than the untreated graphite (O 1s 3.03 at.\%). The incorporation of nitrogen and sulphur-containing functional groups is speculated to assist in the creation of a larger carbon lattice spacing within the $\mathrm{rGO} \mathrm{H}_{2} \mathrm{SO}_{4}$ and $\mathrm{rGO} \mathrm{N}_{2} \mathrm{H}_{4}$ samples, in comparison to the graphite starting material (Fig. 3; Table 2) [35].

Analysis of the dimensions of the rGO particles produced in varied hydrothermal media

Previously, SEM analysis have obtained a display of the larger particulates of the freeze-dried rGO samples and freeze-dried GO preparation (Fig. 1). These images show a highly roughened and agglomerated orientation. The AFM data shows that when the freeze-dried powders are dispersed in solution, the imaging of the smaller particle portion of the whole sample becomes apparent. The isolation of the minute portion of the whole powder sample of the rGO DI $\mathrm{H}_{2} \mathrm{O}, \mathrm{rGO} \mathrm{H}_{2} \mathrm{SO}_{4}$ and graphene oxide preparations is done by suspending the individual whole powder samples in a DMF solution and sonicating these suspensions for 10 minutes. The individual $\mathrm{rGO}$ and GO suspensions stand for 20 minutes followed by decanting of the supernatant, isolating the particulates of smallest mass. This supernatant is then centrifuged at 3,000 rpm for $30 \mathrm{mi}-$ nutes and adherence of the minute particulates to the surface of a silicon substrate is achieved by a simple drop-drying technique. With the thickness of single-layered graphene known to be $\sim 0.34-1 \mathrm{~nm}$, the particle heights observed for the graphene oxide and rGO samples of the AFM data suggest the presence of single- to few-layer graphene nanoparticles being present (Figs. 4 and 5; Table 3) [63, 64].
The dimensions of 110 of the smallest individual particles have been evaluated from AFM images (Fig. 5) of graphene oxide, rGO DI $\mathrm{H}_{2} \mathrm{O}$ and $\mathrm{rGO}_{2} \mathrm{SO}_{4}$ samples, respectively (Table 3). An averaging of the dimensions shows that graphene oxide particles $(1.44 \mathrm{~nm})$ are much thicker in comparison to the rGO samples $(0.50-0.79 \mathrm{~nm})$ (Table 4$)$. This is due to the high amount of oxygen functional groups present in the graphene oxide carbon lattice layers (O 1s 35.63 at.\%), which assist in expansion of the inter-layer spacing as observed by XRD $(7.46 \AA)[65,66]$. The diameter of the minute particles from the GO $(15.69 \mathrm{~nm})$, rGO DI $\mathrm{H}_{2} \mathrm{O}(20.68 \mathrm{~nm})$ and $\mathrm{rGO} \mathrm{H}_{2} \mathrm{SO}_{4}(20.88 \mathrm{~nm})$ samples are similar. The observed dimensions of the rGO show that the exfoliation of the graphene oxide layers during reduction does not cause significant adjustment of the diameter of the particles (Table 3 ).

AFM analysis shows a larger mean particle height for the $\mathrm{rGO} \mathrm{H}_{2} \mathrm{SO}_{4}$ sample in comparison to the $\mathrm{rGO} \mathrm{DI} \mathrm{H}_{2} \mathrm{O}$ sample, most likely resulting from the larger $d$-spacing between the carbon lattices after hydrothermal reduction in $0.1 \mathrm{M}$ sulphuric acid (Tables 2 and 3). The higher oxygen content of the $\mathrm{rGO} \mathrm{H}_{2} \mathrm{SO}_{4}$ (16.06 at.\%) sample may maintain a wider carbon lattice spacing than the rGO DI $\mathrm{H}_{2} \mathrm{O}$ (14.47 at.\%) sample due to more oxygen functional groups between the carbon lattice layers (Tables 3 and 4). The incorporation of sulphur (0.61 at.\%) with its large atomic diameter (100 pm) may also assist in accentuating the spacing between the carbon lattices of the $\mathrm{rGO} \mathrm{H}_{2} \mathrm{SO}_{4}$ sample, thus increasing the detected particle height (Tables 3 and 4). The high standard deviation from the mean diameter of the graphene oxide sample being a
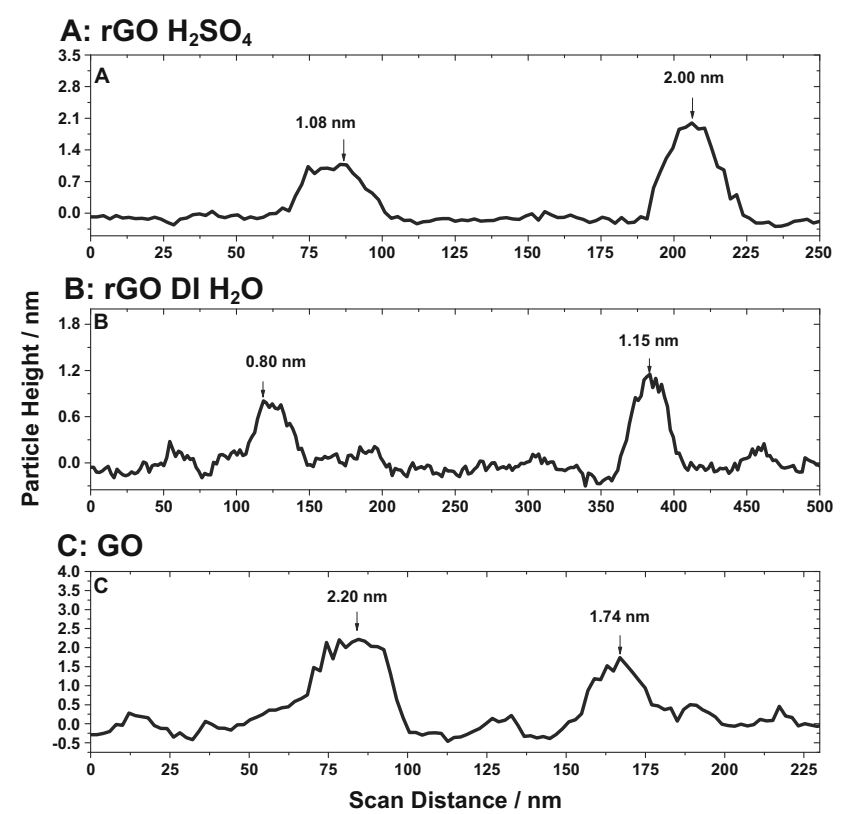

Fig. 4 Single particle profiles of graphene oxide reduced in $0.1 \mathrm{M}$ sulphuric acid $\left(\mathrm{rGO} \mathrm{H}_{2} \mathrm{SO}_{4}\right)(\mathbf{a})$, distilled water $\left(\mathrm{rGO} \mathrm{DI} \mathrm{H}_{2} \mathrm{O}\right)(\mathbf{b})$ and freeze-dried graphene oxide (c) samples. The axis plane used to generate these particle profiles is highlighted by white lines with two blue crosshairs in Fig. 5 
Fig. 5 AFM scan images that generate the data displayed in Fig. 4 and Table 1. AFM images of graphene oxide reduced in sulphuric acid ( $\left.\mathrm{rGO} \mathrm{H}_{2} \mathrm{SO}_{4}\right)($ a), distilled water ( $\mathrm{rGO}$ DI $\left.\mathrm{H}_{2} \mathrm{O}\right)(\mathbf{b})$ and freeze-dried graphene oxide (c) are shown. The positions of the cross section used to generate the particle profiles displayed in Fig. 4 are denoted by a white line with two blue crosshairs
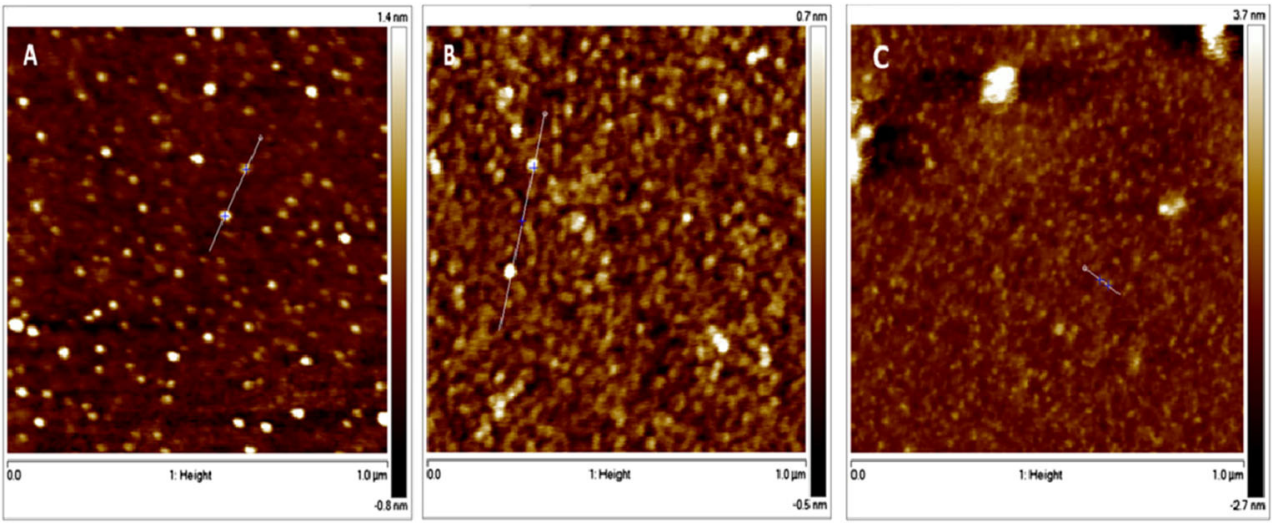

product of the highly varied particle sizes of the starting graphite material, which has a diameter of $<20 \mu \mathrm{m}$ before oxidation by the Hummer's method. The particle heights of the GO and the rGO samples all having a low standard deviation, indicative of the efficacy of the exfoliation techniques employed.

Influence of varied GO reduction media on the composition of the resultant $\mathrm{rGO}$

Assignment of the deconvoluted peaks for the $\mathrm{C} 1 \mathrm{~s}$ analysis are in-line with previous trends observed for graphene-derived materials (Fig. 6) $[6,67,68]$. The $\pi$ - $\pi^{*}$ shake-up satellite peak present at $\sim 291.5 \mathrm{eV}$ is indicative of aromatic $s p^{2}$ carbonbased material [69]. These $\pi-\pi^{*}$ transitions occur from delocalisation of the $\pi$-electrons in the carbon aromatic ring, which does not occur in highly oxidised graphitic materials [5]. This absence of $\pi$-electron delocalisation in the carbon lattice causes severe loss of conductivity after the oxidation of graphite-derived materials. Absence of this $\pi$ - $\pi^{*}$ shake-up peak from the GO sample is also due to the low level of aromatic $s p^{2}$ carbon in the lattice layers, as a result of the high level of oxygenation $[5,6]$. The $\pi-\pi^{*}$ transition peak is present in all of the rGO samples addressed in this study, along with the graphite raw material. This provides an indication of the reduction of graphene oxide, which causes a restoration of the $\pi$-conjugated orbital system [70].

Table 3 Summary of the mean dimensions obtained from atomic force microscopy images of graphene oxide before and after reduction in distilled water $\left(\mathrm{rGO} \mathrm{DI} \mathrm{H}_{2} \mathrm{O}\right)$ and $0.1 \mathrm{M}$ sulphuric acid $\left(\mathrm{rGO} \mathrm{H}_{2} \mathrm{SO}_{4}\right.$ ), respectively

\begin{tabular}{llllll}
\hline $\begin{array}{l}\text { Sample } \\
\text { name }\end{array}$ & $\begin{array}{l}\text { Number } \\
\text { of } \\
\text { particles } \\
\text { analysed }\end{array}$ & $\begin{array}{l}\text { Mean } \\
\text { particle } \\
\text { height } \\
(\mathrm{nm})\end{array}$ & $\begin{array}{l}\text { Particle } \\
\text { height } \\
\text { standard } \\
\text { deviation } \\
(\mathrm{nm})\end{array}$ & $\begin{array}{l}\text { Mean } \\
\text { particle } \\
\text { diameter } \\
(\mathrm{nm})\end{array}$ & $\begin{array}{l}\text { Particle } \\
\text { diameter } \\
\text { standard } \\
\text { deviation } \\
(\mathrm{nm})\end{array}$ \\
\hline Graphene oxide & 110 & 1.44 & \pm 0.20 & 15.69 & \pm 11.37 \\
$\mathrm{rGO} \mathrm{H}_{2} \mathrm{SO}_{4}$ & 110 & 0.79 & \pm 0.051 & 20.88 & \pm 5.63 \\
rGO DI H $\mathrm{H}_{2} \mathrm{O}$ & 110 & 0.50 & \pm 0.043 & 20.68 & \pm 8.48 \\
\hline
\end{tabular}

Figure 6 represents the $\mathrm{C} 1$ s peak of the $\mathrm{rGO}_{2} \mathrm{SO}_{4}$ sample treated at $190{ }^{\circ} \mathrm{C}$ under hydrothermal conditions. The $\mathrm{C} 1 \mathrm{~s}$ peak shows the inclusion of a carbon-sulphur bonding energy at $283.9 \mathrm{eV}$ [67]. This confirms the incorporation of sulphur atoms into the carbon lattice structure from the sulphuric acid molecules during GO reduction [68]. Nascent hydrogen is speculated to assist in the reduction of graphene oxide during exposure to aluminium foil in a hydrochloric acid $(\mathrm{HCl})$ suspension $[15,71]$. The highly acidic environment of the electrolyte promoting a sufficient abundance of nascent hydrogen to facilitate significant deoxygenation of graphene oxide resulting in the release of water. This could be a viable means through which the GO from the current study is reduced while suspended in $0.1 \mathrm{M}$ sulphuric acid during hydrothermal treatment.

Figures $6 \mathrm{e}$ and $7 \mathrm{a}$ indicate the presence of sulphur bonds in the carbon lattice structure of the GO reduced in $0.1 \mathrm{M}$ sulphuric acid. The detection of a $\mathrm{S} 2 \mathrm{p}$ peak at $\sim 169 \mathrm{eV}$ in the $\mathrm{rGO}_{2} \mathrm{SO}_{4}$ sample (Fig. 7a) [72] shows the bonding configuration of sulphur assuming more than one form [73]. Functional groups containing sulphur in the form of $\mathrm{C}-\mathrm{SO}_{2}-\mathrm{C}$ (sulfone group) and $\mathrm{C}-\mathrm{SO}_{3}-\mathrm{C}$ (sulfite group) were observed at 168.5 and $169.5 \mathrm{eV}$, respectively (Fig. 7a) [74]. Figure 7b highlights significant nitrogen incorporation within the carbon lattice structure of the GO reduced by hydrazine, indicated by the presence of an $\mathrm{N} 1 \mathrm{~s}$ peak at $\sim 400 \mathrm{eV}[11,75]$.

Table 4 Summary of XPS data highlighting the relative elemental composition of graphene oxide, graphite and graphene oxide reduced at $190{ }^{\circ} \mathrm{C}$ for 12 hours under high pressure (180-190 psi) in distilled water (rGO DI $\mathrm{H}_{2} \mathrm{O}$ ), $0.33 \mathrm{M}$ hydrazine $\left(\mathrm{rGO} \mathrm{N}_{2} \mathrm{H}_{4}\right)$ and $0.1 \mathrm{M}$ sulphuric acid ( $\mathrm{rGO} \mathrm{H}_{2} \mathrm{SO}_{4}$ ), respectively

\begin{tabular}{|c|c|c|c|c|}
\hline Sample name & C 1s (at.\%) & O 1s (at.\%) & N 1s (at.\%) & S 2p (at.\%) \\
\hline Graphite & 96.97 & 3.03 & - & - \\
\hline Graphene oxide & 64.37 & 35.63 & - & - \\
\hline $\mathrm{rGO} \mathrm{N}_{2} \mathrm{H}_{4}$ & 90.98 & 5.12 & 3.9 & - \\
\hline $\mathrm{rGO} \mathrm{DI} \mathrm{H}_{2} \mathrm{O}$ & 85.53 & 14.47 & - & - \\
\hline $\mathrm{rGO} \mathrm{H}_{2} \mathrm{SO}_{4}$ & 83.30 & 16.09 & - & 0.61 \\
\hline
\end{tabular}


Fig. 6 X-ray photoelectron spectroscopy of the $\mathrm{C} 1 \mathrm{~s}$ spectra of graphene oxide reduced at $190{ }^{\circ} \mathrm{C}$ for 12 hours under high pressure (180-190 psi) in distilled water ( $\mathrm{rGO} \mathrm{DI} \mathrm{H}_{2} \mathrm{O}$ ), $0.1 \mathrm{M}$ sulphuric acid $\left(\mathrm{rGO} \mathrm{H}_{2} \mathrm{SO}_{4}\right)$ and $0.33 \mathrm{M}$ hydrazine $\left(\mathrm{rGO} \mathrm{N}_{2} \mathrm{H}_{4}\right)$, respectively, compared with the starting graphite material and the initial graphene oxide before reduction
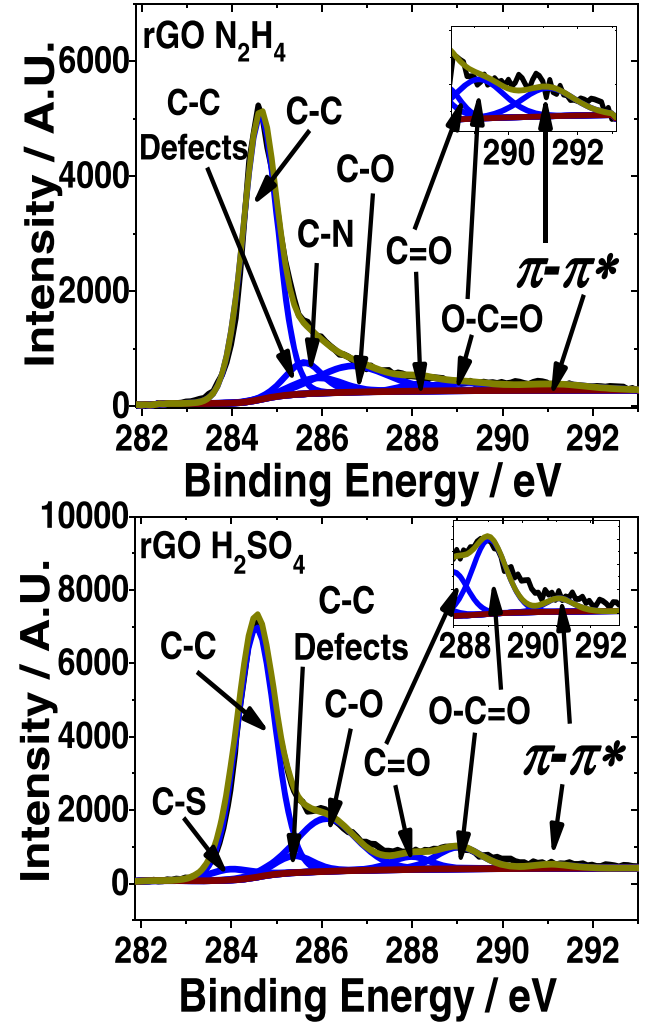

\section{- Measured C 1s Peak Fitted Shirley Baseline Fitted C 1s Peak}

The minute amount of sulphur incorporation after reduction of graphene oxide in sulphuric acid appears to correlate to previous observations involving exposure of graphene oxide to sulphur-containing molecules during reduction $[15,76]$. Avoidance of the employment of common sulphonation molecules for graphenic materials, such as sulfanilic acid, allows the facile hydrothermal method presented by the current study to be relevant for consideration when evaluating strategies for mass production processes [13, 77, 78].

Table 4 provides a summary of the detected elemental distribution of the rGO samples analysed in comparison to the graphite raw material and the graphene oxide starting material.

There is a significant incorporation of nitrogen (3.9 at.\%) into the carbon lattice structure of the rGO
Fig. 7 XPS deconvoluted spectra of $S 2 p$ peak observed in analysis of graphene oxide reduced in $0.1 \mathrm{M}$ sulphuric acid (rGO $\mathrm{H}_{2} \mathrm{SO}_{4}$ ) at $190{ }^{\circ} \mathrm{C}$ for 12 hours under $180 \mathrm{psi}$ (a). N 1s peak observed in graphene oxide reduced in $0.33 \mathrm{M}$ hydrazine $\left(\mathrm{rGO} \mathrm{N} \mathrm{H}_{4}\right)$ at $190{ }^{\circ} \mathrm{C}$ under 190 psi for 12 hours (b)
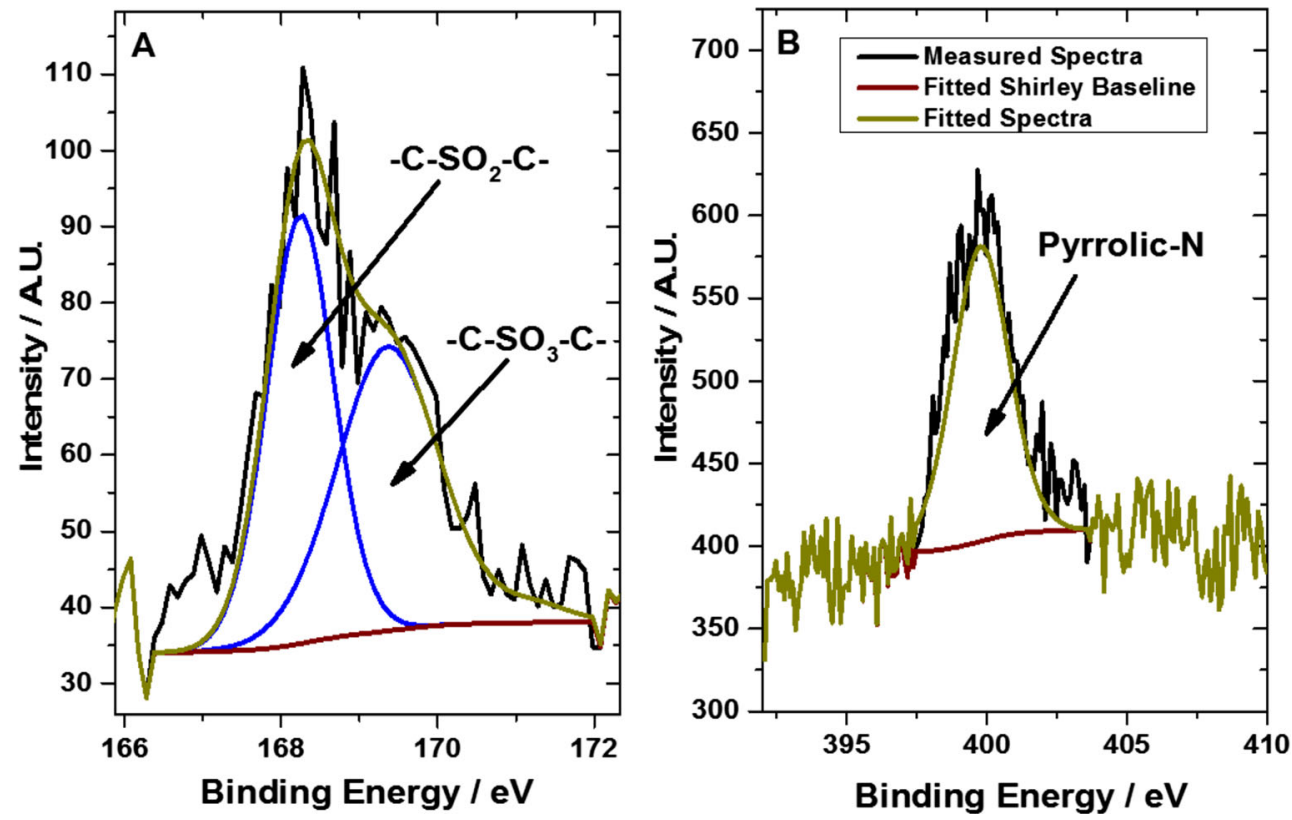
$\mathrm{N}_{2} \mathrm{H}_{4}$ sample produced in the current investigation (Table 4; Fig. 7b). The oxidation of graphite (O 1s 3.03 at.\%) is clearly confirmed by the marked increase of the oxygen content (O 1s 35.63 at.\%) after oxidation. Reduction of the graphene oxide to $\mathrm{rGO}\left(\mathrm{O} 1 \mathrm{~s} \mathrm{rGO} \mathrm{N}_{2} \mathrm{H}_{4}=5.12\right.$ at.\%, rGO $\mathrm{H}_{2} \mathrm{SO}_{4}=16.09$ at.\%, $\mathrm{rGO}$ DI $\mathrm{H}_{2} \mathrm{O}=14.47$ at.\%) is indicated by a decrease in the oxygen content after hydrothermal treatment in the varied media employed (Table 4). The persistence of a certain level of oxygen functionalities is to be expected in the rGO product. Higher oxygen content is observed in the rGO samples than in the raw graphite material (Table 4). However, this significant reduction of graphene oxide being carried out by the proposed single-step treatments of this study are more favourable for a cost-effective delivery of rGO than a multistep solution-based process [13].

Chemical-based GO reduction processes provide functionalised graphene, which in reality differs from that of pristine graphene [79]. GO reduction delivers functionalised graphene sheets and are more costeffective than that of pristine graphene, which is difficult to produce in large quantities and is not easily processible [80]. The mechanisms responsible for the reduction of GO are not entirely understood at present $[11,15]$. Current literature has shed some light on possible reduction mechanisms during the hydrazineassisted production of rGO [81]. One proposed mechanism explains the reduction process being initiated by the opening of the epoxy ring of hydrazine, which requires the removal of hydrogen. This forms a hydrazino $\left(\mathrm{N}_{2} \mathrm{H}_{3}\right)$ compound, which reacts with a hydrazino alcohol $\left(\mathrm{N}_{2} \mathrm{H}_{3}-\mathrm{OH}\right)$ by a transfer of hydrogen, forming water as a by-product [82]. The remaining derivative $\left(-\mathrm{NNH}_{2}\right)$ desorbs once heating begins, allowing the formation of diazene $\left(\mathrm{N}_{2} \mathrm{H}_{2}\right)$, while also incorporating nitrogen into the carbon lattice [81, 82]. However, mechanisms of GO deoxygenation is still mired with a significant degree of uncertainty, which needs clarification before significant advancement of this process [11].

Effect of the reduction media on the ORR catalysis of the rGO preparations

The novel provision of an ORR catalyst by an aqueous suspension of $\mathrm{GO}$ in $0.1 \mathrm{M} \mathrm{H}_{2} \mathrm{SO}_{4}$ during hydrothermal reduction is analysed in comparison to an aqueous suspension without $\mathrm{H}_{2} \mathrm{SO}_{4}\left(\mathrm{rGO}\right.$ DI $\left.\mathrm{H}_{2} \mathrm{O}\right)$. This comparison provides a further novelty in the production of an ORR catalyst by the hydrothermal reduction of GO in only distilled water. Hydrothermal GO reduction in hydrazine acts as a positive control providing a typical electrocatalytic behaviour from the successful reduction of GO resulting from application of the methodology of this study [11]. Figure 8 shows the LSV analysis of the $\mathrm{rGO}$ materials produced in comparison to the current generated from the starting graphite material, graphene oxide and polished $(\Delta E p=\sim 70 \mathrm{mV})$ GCE disc $\left(0.0706 \mathrm{~cm}^{-2}\right)$. For the rGO samples, there is a variation in the capacitive current measured before ORR onset during $\mathrm{O}_{2}$-saturated $0.1 \mathrm{M} \mathrm{KOH}$ electrolyte (Fig. 8a). The highest cathodic current at $-0.1 \mathrm{~V}$ is provided by the $\mathrm{rGO}_{2} \mathrm{SO}_{4}$ sample during $\mathrm{LSV}$ analysis (Fig. 8a). This indicates a capacitive contribution to the overall cathodic current response from analysis in $\mathrm{O}_{2}$ saturated $0.1 \mathrm{M} \mathrm{KOH}$, as no ORR is shown to occur at $-0.1 \mathrm{~V}$. The capacitance at the electrode-electrolyte interface is formed between an excess or deficiency of electrons at the electrode surface and a layer of anions or cations in the electrolyte [83]. This capacitive current contribution to the measurement of the rGO samples needs to be removed to allow observation of only the cathodic current generated from ORR catalysis.

The cathodic current shown for the rGO samples in Fig. 8b is obtained after subtraction of the current obtained during measurement in $\mathrm{N}_{2}$-saturated $0.1 \mathrm{M} \mathrm{KOH}$ from the cathodic current recorded in $\mathrm{O}_{2}$-saturated $0.1 \mathrm{M} \mathrm{KOH} \mathrm{(Fig.} \mathrm{8a).} \mathrm{This}$ allows a subtraction of the capacitive current of the $\mathrm{N}_{2}$-saturated $0.1 \mathrm{M} \mathrm{KOH}$ measurement, leaving only the cathodic current response of ORR catalysis (Fig. 8b). The ORR current of the rGO samples is compared to the $\mathrm{O}_{2}$-saturated current response of the GCE disc $\left(0.0706 \mathrm{~cm}^{-2}\right)$, graphite and graphene oxide measurements (Fig. 8b). No adjustment is made to the $\mathrm{O}_{2}$-saturated current for these samples, as no significant capacitive behaviour was observed from the GCE disc, starting graphite material and graphene oxide during LSV analysis.

Figure $8 \mathrm{~b}$ highlights that the $\mathrm{GO}$ reduced in $0.1 \mathrm{M}$ sulphuric acid has a higher ORR current response in comparison to the rGO DI $\mathrm{H}_{2} \mathrm{O}$ sample during LSV analysis. At $-0.6 \mathrm{~V}$, the cathodic current density is $8.27 \mathrm{~A} \mathrm{~g}^{-1}$ for the rGO $\mathrm{H}_{2} \mathrm{SO}_{4}$ sample, while the $\mathrm{rGO}$ DI $\mathrm{H}_{2} \mathrm{O}$ sample has a lower current $\left(6.57 \mathrm{~A} \mathrm{~g}^{-1}\right)$ (Fig. 8b). The ORR catalysis of the $\mathrm{GO}$ reduced in $0.33 \mathrm{M}$ hydrazine $\left(8.16 \mathrm{~A} \mathrm{~g}^{-1}\right.$ observed at $-0.6 \mathrm{~V}$ ) shows a similar behaviour to that from the rGO $\mathrm{H}_{2} \mathrm{SO}_{4}$ sample (Fig. 8b). The main point to take from Fig. 8 is that the $\mathrm{rGO}_{2} \mathrm{SO}_{4}$ sample ( $\mathrm{pH} \sim 1$ measured from the hydrothermal suspension before and after treatment) provides a similar ORR current response to that of the $\mathrm{rGO} \mathrm{N}_{2} \mathrm{H}_{4}$ sample ( $\mathrm{pH} \sim 10)$. This indicates that the acidity of the medium is not a critical parameter influencing the resultant ORR catalysis observed from the GO reduced. The onset potential of the ORR for the rGO samples does not shift significantly (approximately $-0.12 \mathrm{~V}$ ) regardless of the suspension media applied during reduction. The onset of ORR at approximately $-0.12 \mathrm{~V}$ (Fig. 7) is indicated by a sharp increase in the cathodic current, which initiates the initial two-electron reduction of oxygen in alkaline conditions to the perhydroxyl 


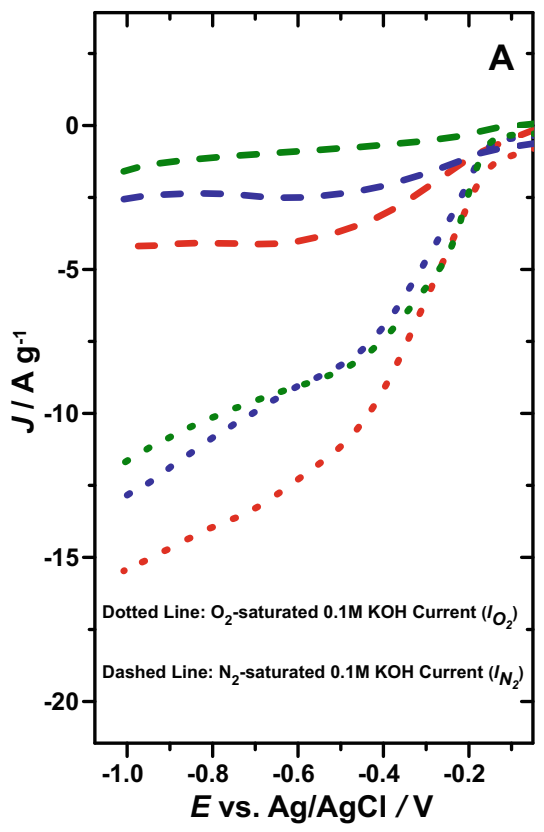

Fig. 8 Linear sweep voltammograms showing measurements in $\mathrm{O}_{2}$ saturated (dotted line) and $\mathrm{N}_{2}$-saturated (dashed line) $0.1 \mathrm{M} \mathrm{KOH}$ from rGO produced by hydrothermal treatment of GO suspended in distilled water $\left(\mathrm{rGO} \mathrm{H} \mathrm{H}_{2} \mathrm{O}\right), 0.1 \mathrm{M}$ sulphuric acid $\left(\mathrm{rGO} \mathrm{H}_{2} \mathrm{SO}_{4}\right)$ and $0.33 \mathrm{M}$ hydrazine ( $\mathrm{rGO} \mathrm{N}_{2} \mathrm{H}_{4}$ ), respectively (a). ORR currents (solid line) are

radical $\left(\mathrm{HO}_{2}{ }^{-}\right)$and a hydroxide anion $\left(\mathrm{OH}^{-}\right)$(Eq. 1) [84, 85]. The first step of ORR shows an initial current maximum at approximately $-0.5 \mathrm{~V}$ for the GCE, graphite, graphene oxide and $\mathrm{rGO} \mathrm{DI} \mathrm{H}_{2} \mathrm{O}$ samples analysed (Fig. 8b). This first reduction step of ORR catalysis is not as apparent in the $\mathrm{rGO} \mathrm{N}_{2} \mathrm{H}_{4}$ and $\mathrm{rGO} \mathrm{H}_{2} \mathrm{SO}_{4}$ samples due to the higher cathodic current resulting from the increase in ORR efficiency (Table 4). This first ORR current step correlates with the current produced by the first two-electron reduction of oxygen (Eq. 1).

$\mathrm{O}_{2}+\mathrm{H}_{2} \mathrm{O} \rightarrow \mathrm{HO}_{2}^{-}+\mathrm{OH}^{-}$

$\mathrm{HO}_{2}^{-}+\mathrm{H}_{2} \mathrm{O} \rightarrow 3 \mathrm{OH}^{-}$

The second stage of ORR (Eq. 2) involves the reduction of the perhydroxyl radical and water to hydroxide anions [84, 85]. The additional slight increase in cathodic current at approximately $-0.7 \mathrm{~V}$, most apparent for LSV scans of the GCE, graphite, graphene oxide and $\mathrm{rGO} \mathrm{DI}_{2} \mathrm{O}$ sample (Fig. 8b), correlates to this second step in ORR catalysis (Eq. 2). This second reaction onset would not be clearly observable where the ORR is close to or comprises of a single four-electron reaction step, as is seen for the LSV scan taken of $\mathrm{Pt} / \mathrm{C}$ shown in the supporting information (Fig. S3) [86].

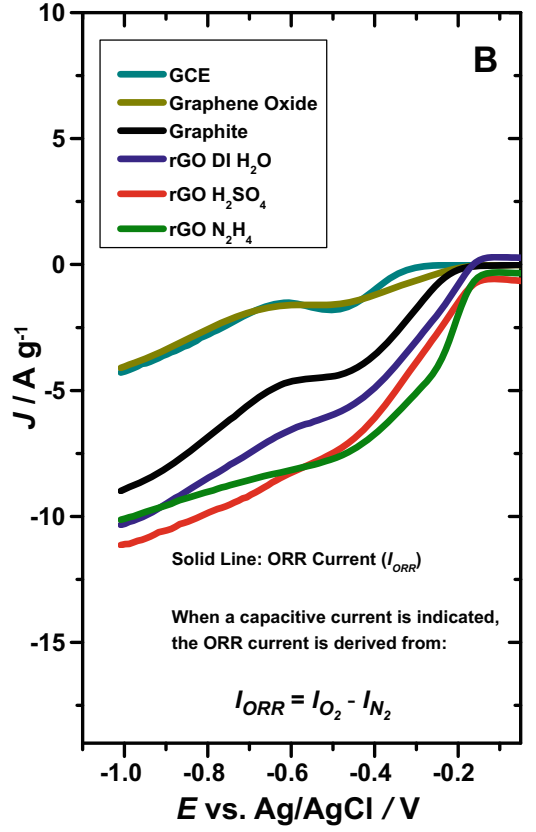

derived from the rGO samples measured in $\mathrm{O}_{2}$ - and $\mathrm{N}_{2}$-saturated $0.1 \mathrm{M}$ $\mathrm{KOH}$ and are compared to the current response from the polished GCE disc $\left(\Delta E p=\sim 70 \mathrm{mV} ; 0.0706 \mathrm{~cm}^{2}\right)$, graphene oxide and graphite preparations (b). Treatment conditions for hydrothermal production are at $190^{\circ} \mathrm{C}$ for 12 hours under high pressure (180-190 psi). Scan rate is $10 \mathrm{mV} \mathrm{s}^{-1}$

The presence of sulphur binding to carbon provides a plausible cause for the increase in the ORR response obtained from the $\mathrm{rGO}_{2} \mathrm{SO}_{4}$ sample. Previously, the incorporation of minute amounts of sulphur (1.30 at.\%) into graphene particles derived from graphene oxide reduction has contributed to the enhancement of ORR catalysis [87]. A small amount of sulphur incorporation can assist in the provision of a higher cathodic current density than platinum on carbon black during LSV analysis [87]. Previously, the incorporation of sulphur was 0.60 at. $\%$ after GO reduction in sulphuric acid within a solvent suspension [35], and this current study relays similar results with 0.61 at. $\%$ of sulphur reported for the $\mathrm{rGO} \mathrm{H}_{2} \mathrm{SO}_{4}$ sample. The exact role of sulphur in metal-free ORR catalysts is a topical issue at present [88-90]. Sulphur atoms have a larger atomic radius $(100 \mathrm{pm})$ than that of other heteroatoms, such as nitrogen $(65 \mathrm{pm})$ [91]. The incorporation of a sulphur atom can create a higher level of physical disruption than nitrogen incorporation, thus providing a higher level of structural defects and ORR active sites. A sulphur atom has lone pair polarisable $d$-orbitals, which promote interactions with molecules in the electrolyte, delivering a more conducive ORR catalytic material [88].

$\mathrm{Lu}$ et al. reported that nitrogen doping of rGO has previously proven successful at developing an ORR catalyst with significant opportunity for up-scaling synthesis [92]. An ORR onset potential of $-0.231 \mathrm{~V}$ for $\mathrm{N}-\mathrm{rGO}$ provided by $\mathrm{Lu}$ et al. 
shows that the rGO samples produced in the current study require less overpotential to initiate ORR (approximately $-0.12 \mathrm{~V})$. This indicates a more favourable ORR catalysis for the rGO DI $\mathrm{H}_{2} \mathrm{O}, \mathrm{rGO} \mathrm{H}_{2} \mathrm{SO}_{4}$ and $\mathrm{rGO} \mathrm{N}_{2} \mathrm{H}_{4}$ samples. Wu et al. disclosed rGO produced from GO reduction by hydrazine which provided $\sim 3 \mathrm{~mA} \mathrm{~cm}^{-2}$ at $-0.6 \mathrm{~V}$ during LSV measurements taken at 1,200 rpm [93]. While the current density of the 1,200 rpm measurement of the $\mathrm{rGO} \mathrm{N}_{2} \mathrm{H}_{4}$ sample in the current study is $3.05 \mathrm{~mA} \mathrm{~cm}^{-2}(0.215 \mathrm{~mA})$ at $-0.6 \mathrm{~V}$. The ORR current provided by the hydrothermal GO reduction process with $0.33 \mathrm{M}$ hydrazine suspension in this study is similar to the room pressure hydrazine-based reduction processes commonly applied to other studies $[11,93]$.

Another ORR catalysis study focuses on an electrode coating consisting of bi-layer poly(diallyldimethylammonium chloride) (PDDA) and reduced graphene oxide material. Numerous bi-layers yield an ORR onset potential movement to as much as $-0.11 \mathrm{~V}$ [94]. This is similar to the rGO samples of the current study $(-0.12 \mathrm{~V})$, while the highest ORR cathodic current from LSV analysis is observed to be $1.22 \mathrm{~mA} \mathrm{~cm}^{-2}$ at $-0.6 \mathrm{~V}$ for the $\mathrm{rGO} / \mathrm{PDDA}$ composite catalyst layer [94]. The $\mathrm{rGO} \mathrm{DI} \mathrm{H}_{2} \mathrm{O}\left(2.79 \mathrm{~mA} \mathrm{~cm}^{-2}\right), \mathrm{rGO} \mathrm{N}_{2} \mathrm{H}_{4}\left(3.46 \mathrm{~mA} \mathrm{~cm}^{-2}\right)$ and rGO $\mathrm{H}_{2} \mathrm{SO}_{4}\left(3.51 \mathrm{~mA} \mathrm{~cm}^{-2}\right.$ ) samples (current densities are in milliampere per square centimetre $\left(\mathrm{mA} \mathrm{cm}^{-2}\right)$, which were calculated from Fig. $8 \mathrm{~b}$ using the area of the substrate GCE disc) from the current study all provide a higher current density at $-0.6 \mathrm{~V}$ than the $\mathrm{rGO} / \mathrm{PDDA}$ composite reported. This further highlights the advantage of the hydrothermal reduction process proposed in this study. An ORR catalyst using rGO in a composite with Au nanoparticles have provided an ORR onset of approximately $-0.3 \mathrm{~V}$ (vs. $\mathrm{Ag} / \mathrm{AgCl}$ ) during LSV analysis [95]. Incorporation of iron, cobalt and nitrogen into rGO non-precious metal catalysts (NPMCs) has enhanced ORR catalysis [96]. This is indicated by Fu et al. with a reported onset potential during LSV analysis of approximately $+0.05 \mathrm{~V}$ (vs. $\mathrm{Ag} / \mathrm{AgCl}$ (saturated $\mathrm{KCl}$ ) reference electrode), which was seen to require less overpotential than a Pt/C coating prepared on a GCE disc [96]. Other applications for nitrogen-doped rGO preparations have shown success as a support substrate for electrocatalytic platinum nanoparticles. The employment of N-rGO as a catalyst support enhances the ORR onset potential during LSV analysis of the platinum nanoparticles by minimising the amount of overpotential required to initiate electrocatalysis [97]. For future development of the rGO samples of the current study, there is much opportunity for broadening the scope of experimental investigations to identify additional applications.

Comparison of the rGO samples developed with that of the optimum ORR response obtained from $\mathrm{Pt} / \mathrm{C}$ is shown in Fig. S3 of the supporting information. Figure S3 highlights the level of improvement required from the rGO samples before replication of the ORR catalysis from $\mathrm{Pt} / \mathrm{C}$ can be realised. The catalytic enhancement of the developed rGO materials is another vital consideration to include during further development so that the $\mathrm{Pt} / \mathrm{C}$ may be replaced by a suitable non-metal electrocatalyst during the construction of fuel cell technologies. A recent study also highlights the suitability of sulfonated reduced graphene oxide as a support material for electrocatalytic platinum nanoparticles, which efficiently provide a stable ORR current [58]. This may be another consideration for the $\mathrm{rGO}_{2} \mathrm{SO}_{4}$ sample of this study, bringing merit to future work.

Effect of varied GO reduction suspension on ORR efficiency

The $\mathrm{rGO} \mathrm{H}_{2} \mathrm{SO}_{4}$ sample ( $n=2.8$ at $\left.-0.6 \mathrm{~V}\right)$ indicates a slightly higher electron transfer number to that obtained for GO reduced with hydrazine $(n=2.2$ at $-0.6 \mathrm{~V})$. This result coupled with the LSV comparison indicates that the ORR response is similar for $\mathrm{rGO}_{2} \mathrm{SO}_{4}$ sample and $\mathrm{rGO} \mathrm{N}_{2} \mathrm{H}_{4}$ sample. The kinetics calculated for the rGO DI $\mathrm{H}_{2} \mathrm{O}$ sample $(n=2.3$ at $-0.6 \mathrm{~V}$ ), along with the accompanying LSV analysis, would suggest that the rGO DI $\mathrm{H}_{2} \mathrm{O}$ sample provides a lower ORR catalysis than the $\mathrm{rGO} \mathrm{H}_{2} \mathrm{SO}_{4}$ sample (Table 5; Fig. 8).

The electron transfer number calculations for the $\mathrm{rGO}$ samples developed are compared to $\mathrm{Pt} / \mathrm{C}$ (Table 4). All of the rGO samples fall short of the ideal four-electron transfer efficiency displayed by the $\mathrm{Pt} / \mathrm{C}$ coating. The rGO ORR efficiency calculations were derived from the LSV scans (Fig. 9) taken at varied rotation rates. ORR catalysis is further indicated to occur at the surface of the rGO samples during LSV analysis as the current magnitude increases with a higher rotation rate applied to the glassy carbon RDE while submerged in $\mathrm{O}_{2}$-saturated electrolyte [93].

$\mathrm{Pt} / \mathrm{C}$ ORR efficiency calculations have also been derived from LSV measurements taken at varied rotation rates using a $0.283 \mathrm{mg} \mathrm{cm}^{-2}$ coating on a GCE disc (Table 4; Fig. S4). The calculation of the electron transfer numbers of the rGO

Table 5 The calculated electron transfer $(n)$ numbers per reduced dioxygen molecule for $\mathrm{GO}$ reduced at $190{ }^{\circ} \mathrm{C}$ for 12 hours in distilled water $\left(\mathrm{rGO} \mathrm{DI} \mathrm{H}_{2} \mathrm{O}\right), 0.1 \mathrm{M}$ sulphuric acid $\left(\mathrm{rGO} \mathrm{H}_{2} \mathrm{SO}_{4}\right)$ and $0.33 \mathrm{M}$ hydrazine $\left(\mathrm{rGO} \mathrm{N}_{2} \mathrm{H}_{4}\right)$, respectively, under high pressure $(180-190 \mathrm{psi})$

Potential versus Electron transfer $(n)$ number per reduced dioxygen $\mathrm{Ag} / \mathrm{AgCl}(\mathrm{V}) \quad$ molecule

\begin{tabular}{lllll}
\cline { 2 - 5 } & $\mathrm{rGO} \mathrm{DI} \mathrm{H}_{2} \mathrm{O}$ & $\mathrm{rGO} \mathrm{H}_{2} \mathrm{SO}_{4}$ & $\mathrm{rGO} \mathrm{N}_{2} \mathrm{H}_{4}$ & $\mathrm{Pt} / \mathrm{C}$ \\
\hline-0.5 & 2.0 & 2.5 & 2.1 & 4.0 \\
-0.6 & 2.3 & 2.8 & 2.2 & 4.2 \\
-0.7 & 2.5 & 2.9 & 2.3 & 4.1 \\
\hline
\end{tabular}

rGO material coating on the GCE substrate was $0.424 \mathrm{mg} \mathrm{cm}^{-2}$. Included for comparison purposes is the $n$-numbers for a $0.283 \mathrm{mg} \mathrm{cm}^{-2}$ coating of platinum, nominally $20 \%$ on carbon black $(\mathrm{Pt} / \mathrm{C})$ 
Fig. 9 Linear sweep voltammograms highlighting the effect of varied rotation rates of the working electrode upon a $0.424 \mathrm{mg} \mathrm{cm}^{-2}$ coating of graphene oxide reduced at $190{ }^{\circ} \mathrm{C}$ for 12 hours in distilled water (rGO DI $\mathrm{H}_{2} \mathrm{O}$ ), $0.33 \mathrm{M}$ hydrazine $\left(\mathrm{rGO} \mathrm{N} \mathrm{H}_{4}\right.$ ) and $0.1 \mathrm{M}$ sulphuric acid $\left(\mathrm{rGO} \mathrm{H}_{2} \mathrm{SO}_{4}\right.$ ), respectively, at high pressure (180-190 psi). $\mathrm{Scan}$ rate is $10 \mathrm{mV} \mathrm{s}^{-1}$. All scans are a product of an LSV scan measured in $\mathrm{O}_{2}$-saturated $0.1 \mathrm{M}$ $\mathrm{KOH}$ minus the current generated from another LSV scan taken in $\mathrm{N}_{2}$-saturated $0.1 \mathrm{M} \mathrm{KOH}$ at an equivalent working electrode rotation rate. This allows only the cathodic current generated from the ORR to be displayed. GCE disc substrate being used for analysis has an area of $0.0706 \mathrm{~cm}^{2}$
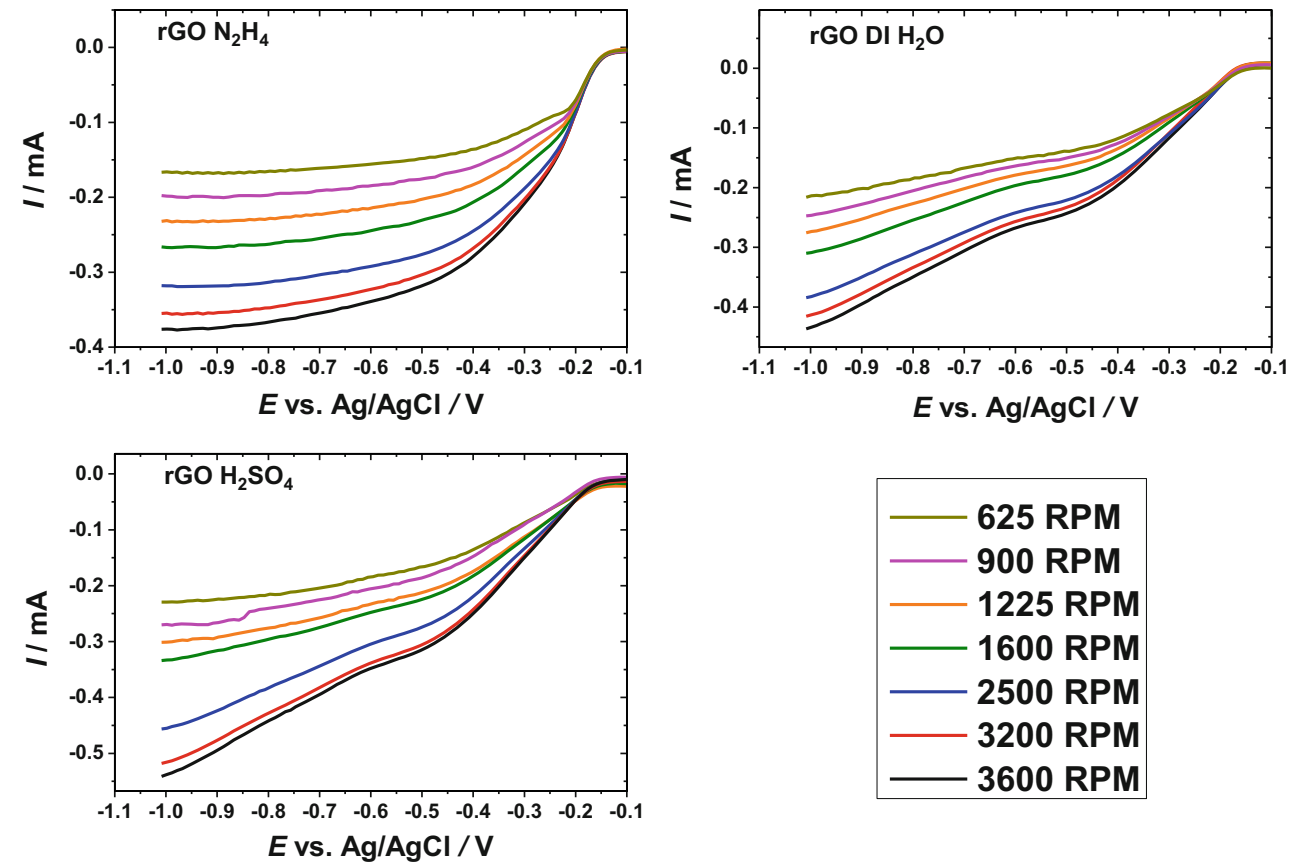

Es. $\mathrm{Ag} / \mathrm{AgCl} / \mathrm{V}$

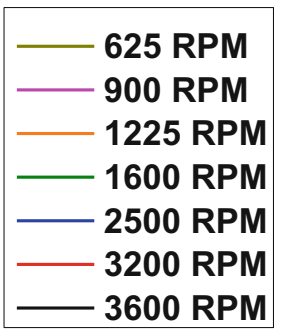

samples is derived through application of the $\mathrm{K}-\mathrm{L}$ equation, which uses the slope values from a linear fit of the data displayed in the $\mathrm{K}-\mathrm{L}$ plot (Fig. 10). The K-L calculation (Eq. S1) was developed initially for analysis at a planar electrode [98-100]. Recent success in applying this equation to analysis of non-planer particulate surfaces has encouraged application of the $\mathrm{K}-\mathrm{L}$ equation in the present investigation [87, 101-104].

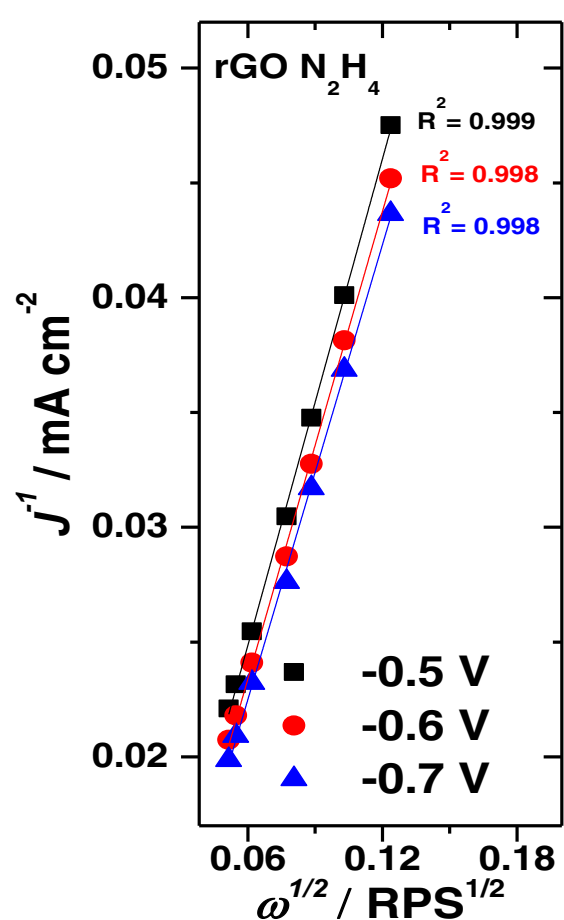

Fig. $10 \mathrm{~K}-\mathrm{L}$ plots for graphene oxide reduced at $190{ }^{\circ} \mathrm{C}$ at high pressure (180-190 psi) in $0.33 \mathrm{M}$ hydrazine $\left(\mathrm{rGO} \mathrm{N}_{2} \mathrm{H}_{4}\right.$ ), distilled water (rGO DI $\mathrm{H}_{2} \mathrm{O}$ ) and $0.1 \mathrm{M}$ sulphuric acid $\left(\mathrm{rGO} \mathrm{H}_{2} \mathrm{SO}_{4}\right)$, respectively. The slopes of the K-L plots were used to calculate the $n$-number with application of the $\mathrm{K}-\mathrm{L}$ equation. Graphed is the inverse square root of the angular frequency $\left(\left(\omega^{-1 / 2}\right)\right.$, given in rotations per second $\left.(R P S)\right)$ of the rotation rates of the
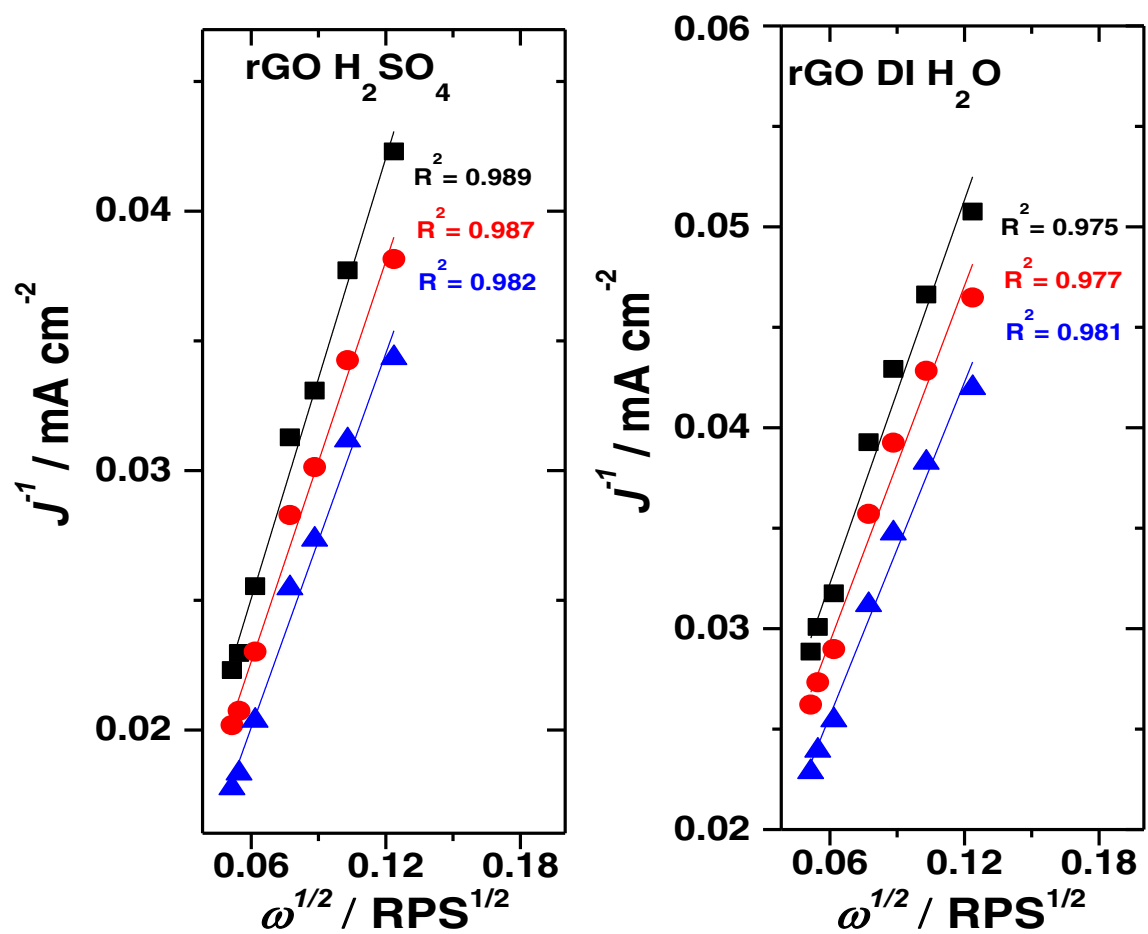

glassy carbon working electrode disc in relation to the change in the inverse current density $\left(J^{-1} / \mathrm{A} \mathrm{m}^{-2}\right)$ observed. This current density is obtained from the LSV scans displayed in Fig. 9 at $-0.5,-0.6$ and $-0.7 \mathrm{~V}$. Current densities were calculated with respect to the surface area of the glassy carbon disc substrate $\left(0.0706 \mathrm{~cm}^{2}\right)$ 
In another study, an rGO/PDDA bi-layered catalyst $(n=$ $\sim 2.85$ at $-0.6 \mathrm{~V}$ ) shows comparable ORR efficiency to that of the $\mathrm{rGO} \mathrm{H}_{2} \mathrm{SO}_{4}$ sample $(n=\sim 2.8$ at $-0.6 \mathrm{~V})$ of this current investigation [94], while a nitrogen-doped $\mathrm{rGO}(n=3.7)$ preparation highlights an ORR efficiency close to that of the ideal four-electron ORR catalysis facilitated by $\mathrm{Pt} / \mathrm{C}$ [92]. This nitrogen-doped rGO was produced by pyrolysis of Hummer's graphene oxide with 5-aminotetrazole monohydrate (AM) under a $\mathrm{N}_{2}$-rich ambient environment [92]. The enhancement of ORR on the N-rGO produced after pyrolysis of GO with $\mathrm{AM}$ is due to the increased defects caused by the high level of nitrogen incorporation (10.6 at.\%), along with the significant edge plane exposure of the N-rGO particles [92]. Another study involving graphene sheets delivered by hydrazine reduction at room pressure have indicated an electron transfer of $\sim 3.2$ at $-0.6 \mathrm{~V}$ [93]. These previously reported rGO preparations highlight the rGO samples of this study to be comparable to some of the findings of other investigations, while also bringing to light the opportunity for further enhancement.

The specific surface area values of the $\mathrm{rGO} \mathrm{H}_{2} \mathrm{SO}_{4}$ sample is of most interest as the most enhanced ORR catalysis of the developed rGO samples is provided after reduction in sulphuric acid. The graphite powder used to deliver graphene oxide in this study was observed to have a BET [105] specific surface area value of $14.36 \mathrm{~m}^{2} \mathrm{~g}^{-1}$ (Fig. S7). Graphene oxide has been shown to provide a specific surface area of $68-161 \mathrm{~m}^{2} \mathrm{~g}^{-1}[37,74,106]$, which correlates with the freeze-dried graphene oxide sample of this study $\left(102.29 \mathrm{~m}^{2} \mathrm{~g}^{-1}\right)$.

In the present study, graphene oxide reduced in $0.1 \mathrm{M}$ sulphuric acid resulted in a specific surface area $\left(114.77 \mathrm{~m}^{2} \mathrm{~g}^{-1}\right)$ that increased after hydrothermal treatment. The abrasive action of the reduction process appears to increase the specific surface area of $\mathrm{rGO}_{2} \mathrm{SO}_{4}$ (Fig. S7) without noticeably affecting the appearance after reduction, as shown from SEM analysis (Fig. 1). The increase in the width of the hysteresis in the $\mathrm{GO}$ after hydrothermal reduction in $0.1 \mathrm{M} \mathrm{H}_{2} \mathrm{SO}_{4}$ indicates an enhancement of porosity with an increase of the pore size distribution [107, 108]. A high level of porosity within a graphenic material has been noted to enhance electrochemical behaviour [44, 109-111]. The more pores available on the surface, the higher the contact surface area with the electrolyte, providing opportunity for an enhanced abundance of ORR active sites. This being the most likely avenue through which the increased surface area of the rGO $\mathrm{H}_{2} \mathrm{SO}_{4}$ contributes to the enhanced ORR catalysis observed (Fig. 8).

Investigation of the capacitive behaviour of graphene oxide reduced in varied media during hydrothermal treatment

During analysis of the ORR current, the capacitive response is shown to be significant for the reduced graphene oxide samples (Fig. 8), indicated by the varied current magnitudes before ORR onset during LSV analysis. A RDE provides a constant flow of electrolyte to the working electrode surface during analysis. The force exerted on the electrode surface by the electrolyte flow during LSV analysis needs to be removed to facilitate an undistorted observation of the capacitive current generated at the surface of the rGO coating. Cyclic voltammetry is employed to measure the rGO samples at a stagnant GCE working electrode, permitting observation of any capacitive effect without adjustments from the flow of electrolyte to the electrode surface. Figure 11 displays a comparison of the anodic and cathodic current response during cyclic voltammetry analysis of the graphene oxide reduced in distilled water, $0.1 \mathrm{M}$ sulphuric acid and $0.33 \mathrm{M}$ hydrazine, respectively. The graphene oxide, untreated graphite and the bare GCE disc are also included for comparison purposes. The current detected during cyclic voltammetry analysis in $\mathrm{O}_{2}-$, air-, $\mathrm{N}_{2}$-saturated $0.1 \mathrm{M} \mathrm{KOH}$ electrolyte are compared for each sample preparation (Fig. 11).

The CV evaluations of the $\mathrm{rGO}$ DI $\mathrm{H}_{2} \mathrm{O}$ sample show that the current response does not adjust significantly to changes in dissolved oxygen concentrations. The $\mathrm{rGO} \mathrm{DI}_{2} \mathrm{O}$ sample at $-0.312 \mathrm{~V}$ provides a cathodic current of $13.67 \mathrm{~A} \mathrm{~g}^{-1}$ in $\mathrm{O}_{2}$ saturated $\mathrm{KOH}, 14.67 \mathrm{~A} \mathrm{~g}^{-1}$ in air-saturated $\mathrm{KOH}$ and $13.47 \mathrm{~A} \mathrm{~g} \mathrm{~g}^{-1}$ being observed in $\mathrm{N}_{2}$-saturated $\mathrm{KOH}$ electrolyte. The current density at $-0.312 \mathrm{~V}$ being most relevant due to the oxygen reduction peak indicated at approximately $-0.312 \mathrm{~V}$ for the rGO preparations, as was confirmed for the $\mathrm{rGO} \mathrm{N}_{2} \mathrm{H}_{4}$ sample during $\mathrm{CV}$ analysis in $\mathrm{O}_{2}$-saturated $0.1 \mathrm{M} \mathrm{KOH}$ (Fig. 11). Any change in the cathodic current as a result of the oxygen reduction should be detectable at approximately $-0.312 \mathrm{~V}$. The $\mathrm{rGO} \mathrm{H}_{2} \mathrm{SO}_{4}$ sample also shows an even higher degree of similarity in the cathodic current response between the $\mathrm{N}_{2}$-saturated (18.67 $\mathrm{A} \mathrm{g}^{-1}$ ), air-saturated $\left(19.67 \mathrm{~A} \mathrm{~g}^{-1}\right)$ and $\mathrm{O}_{2}$-saturated $\left(20.21 \mathrm{~A} \mathrm{~g}^{-1}\right) 0.1 \mathrm{M}$ $\mathrm{KOH}$ assessments at $-0.312 \mathrm{~V}$. Although the current may change slightly from catalysis at the developed rGO surface in response to variation in the dissolved $\mathrm{O}_{2}$ of the electrolyte, there is a reliable pseudocapacitance that is not modified significantly (Fig. 11).

The distinct ORR peak for the $\mathrm{rGO}_{2} \mathrm{H}_{4}$ sample measured in $\mathrm{O}_{2}$-saturated $0.1 \mathrm{M} \mathrm{KOH}$ provides a cathodic current of $8.33 \mathrm{~A} \mathrm{~g}^{-1}$ at $-0.312 \mathrm{~V}$, while a decreased cathodic current is observed from air-saturated $\left(6.19 \mathrm{~A} \mathrm{~g}^{-1}\right)$ and $\mathrm{N}_{2}$-saturated (5.20 $\mathrm{A} \mathrm{g}^{-1}$ ) scans (Fig. 11). This sequential decrease of the cathodic current with a decrease in dissolved $\mathrm{O}_{2}$, seems to be due to the decrease in the magnitude of the ORR catalysis. The graphene oxide reduced in $0.1 \mathrm{M}$ sulphuric acid provides the highest magnitude of the cathodic and anodic current response at $-0.312 \mathrm{~V}$ in comparison to the other $\mathrm{rGO}$ samples analysed (Fig. 11).

At $-0.312 \mathrm{~V}$, the graphite sample provides a low-level cathodic current in $\mathrm{O}_{2}$-saturated $\left(1.11 \mathrm{~A} \mathrm{~g}^{-1}\right)$, air-saturated 
Fig. 11 Cyclic voltammetry measured in $\mathrm{O}_{2}$-saturated (black), $\mathrm{N}_{2}$-saturated (red) and airsaturated (blue) $0.1 \mathrm{M} \mathrm{KOH}$ highlighting the current response of graphene oxide reduced in distilled water ( $\left.\mathrm{rGO} \mathrm{DI} \mathrm{H}_{2} \mathrm{O}\right)$, $0.1 \mathrm{M}$ sulphuric acid (rGO $\mathrm{H}_{2} \mathrm{SO}_{4}$ ) and $0.33 \mathrm{M}$ hydrazine $\left(\mathrm{rGO} \mathrm{N}{ }_{2} \mathrm{H}_{4}\right.$ ), respectively. Comparison is also made to $\mathrm{CV}$ scans of graphene oxide, graphite and a polished GCE disc ( $\triangle E p=$ $70 \mathrm{mV}$ ). Catalyst coatings $\left(0.424 \mathrm{mg} \mathrm{cm}^{-2}\right)$ were measured at a scan rate of $100 \mathrm{mV} \mathrm{s}^{-1}$
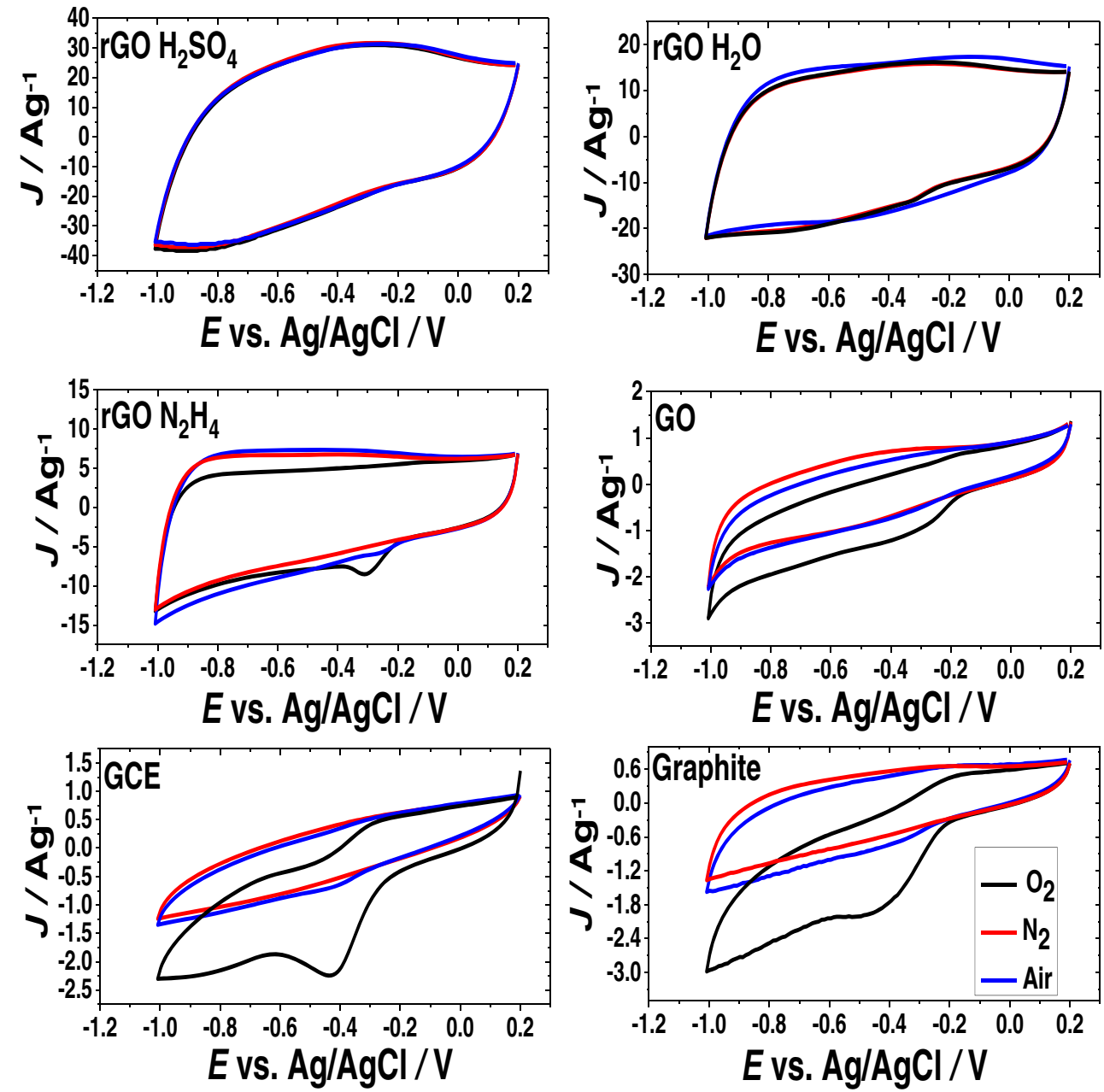

$\left(0.53 \mathrm{~A} \mathrm{~g}^{-1}\right)$ and $\mathrm{N}_{2}$-saturated $\left(0.43 \mathrm{~A} \mathrm{~g}^{-1}\right) 0.1 \mathrm{M} \mathrm{KOH}$, which decreases noticeably with a lowering of the dissolved oxygen level in the electrolyte. A similar trend is also observed for graphene oxide in $\mathrm{O}_{2}$-saturated $\left(0.97 \mathrm{~A} \mathrm{~g}^{-1}\right)$, air-saturated $\left(0.50 \mathrm{~A} \mathrm{~g}^{-1}\right)$ and $\mathrm{N}_{2}$-saturated $\left(0.47 \mathrm{~A} \mathrm{~g}^{-1}\right) 0.1 \mathrm{M} \mathrm{KOH}$ electrolyte at $-0.312 \mathrm{~V}$. There is no distinctive capacitive behaviour for the graphite, graphene oxide or the bare GCE disc (Fig. 11). The dominant faradaic cathodic current is provided from ORR catalysis. This is indicated by the magnitude of cathodic current increasing substantially as the level of dissolved oxygen increases within the $0.1 \mathrm{M} \mathrm{KOH}$ electrolyte for the $\mathrm{CV}$ analysis of the polished GCE, graphite and graphene oxide preparations (Fig. 11). The ORR magnitude is not seen to significantly affect the current response from $\mathrm{CV}$ analysis of the rGO DI $\mathrm{H}_{2} \mathrm{O}$ and $\mathrm{rGO}_{2} \mathrm{SO}_{4}$ samples. Other mechanisms are indicated to be responsible for this distinct pseudocapacitive behaviour. In Fig. 11, there is a noticeable depressed oxidation peak in the $\mathrm{rGO}_{2} \mathrm{SO}_{4}$ sample at approximately $-0.3 \mathrm{~V}$, while a broad attenuated reduction peak is apparent within the potential range of $-0.4 \mathrm{~V}$ to $-0.9 \mathrm{~V}$, indicating a slight redox reaction occurring. For the $\mathrm{rGO} \mathrm{H}_{2} \mathrm{SO}_{4}$ sample, this redox reaction is apparent regardless of the level of dissolved oxygen content in the $0.1 \mathrm{M} \mathrm{KOH}$ electrolyte (Fig. 11). Also, for the rGO DI $\mathrm{H}_{2} \mathrm{O}$ sample measured in $\mathrm{O}_{2}$-saturated and $\mathrm{N}_{2}$-saturated $0.1 \mathrm{M} \mathrm{KOH}$, the $\mathrm{CV}$ data shows a slight redox reaction with attenuated current peaks at $-0.3 \mathrm{~V}$ for the anodic oxidation reaction and again from -0.4 to $-0.8 \mathrm{~V}$ during the cathodic reduction reaction. For the air-saturated measurement of the rGO DI $\mathrm{H}_{2} \mathrm{O}$ sample, this redox behaviour seems to culminate in an oxidation peak at $-0.1 \mathrm{~V}$, while a slight cathodic reduction peak is present at $-0.5 \mathrm{~V}$.

A possible explanation for the redox peaks present during $\mathrm{CV}$ analysis of the $\mathrm{rGO}$ DI $\mathrm{H}_{2} \mathrm{O}$ and $\mathrm{rGO}_{2} \mathrm{SO}_{4}$ samples (Fig. 11) is the presence of quinone derivatives and other carbonyl-containing oxygen groups on the surface of the reduced graphene oxide [11]. Even after the reduction of GO using the varied methods of this study, there is still a significant oxygen content remaining, as highlighted by XPS analysis (Table 4). This could comprise of quinone carbonyl groups at the surface of the rGO samples, promoting a redox behaviour during voltammetric analysis [112-116]. It is speculated that these adhered quinone derivatives provide a 
faradaic current contribution to the pseudocapacitive response observed from the $\mathrm{rGO} \mathrm{H}_{2} \mathrm{SO}_{4}$ and $\mathrm{rGO}$ DI $\mathrm{H}_{2} \mathrm{O}$ samples [117]. The redox potential of surface-bound quinone derivatives varies in relation to the different types of quinone moieties present at an electroactive surface [117]. This is a possible explanation for the slight variation in the attenuated redox peak positions of the rGO DI $\mathrm{H}_{2} \mathrm{O}$ sample measured in $\mathrm{O}_{2}$-saturated and $\mathrm{N}_{2}$-saturated $0.1 \mathrm{M} \mathrm{KOH}$ measurements in comparison to the air-saturated $\mathrm{CV}$ analysis [118].

The current response during voltammetric analysis may also be partially due to oxygen reduction catalysed at these quinone groupings on the rGO surface, although the exact mechanism involved is not definitively agreed upon among current literature [119]. ORR is seen to be predominantly a two-step, two-electron process at quinone-based electrode coatings, placing quinone catalysts as an ideal material for the production of hydrogen peroxide in acidic electrolyte [117-119]. The variation in the current density of the rGO $\mathrm{N}_{2} \mathrm{H}_{4}$, rGO DI $\mathrm{H}_{2} \mathrm{O}$ and $\mathrm{rGO} \mathrm{H}_{2} \mathrm{SO}_{4}$ samples, as shown at $-0.312 \mathrm{~V}$ in $\mathrm{N}_{2}$-saturated, $\mathrm{O}_{2}$-saturated and air-saturated $\mathrm{KOH}$, proves that there is a low-level faradaic current contribution from the oxygen reduction reaction (Fig. 11). The reduction of oxygen to the perhydroxyl radical $\left(\mathrm{HO}_{2}{ }^{-}\right)$ involves a two-electron transfer, providing a well-defined cathodic current peak at the polished GCE, $\mathrm{rGO} \mathrm{N}_{2} \mathrm{H}_{4}$, graphite and graphene oxide material coatings (Fig. 11).

Figure 12 confirms the persistence of a pseudocapacitive response in the current measured from $\mathrm{CV}$ analysis of the $\mathrm{rGO}$ samples during a change in the scan rate of the potential sweep in air-saturated $0.1 \mathrm{M} \mathrm{KOH}$. A persistent capacitive current response, while under the influence of varied scan rates, is a typical behaviour for reduced graphene oxide [14]. Airsaturated $0.1 \mathrm{M} \mathrm{KOH}$ is used for $\mathrm{CV}$ analysis displayed in Fig. 12. Air-saturated electrolyte is used as a representative of the current response during $\mathrm{CV}$ analysis from the $\mathrm{rGO}$ samples developed ( $\mathrm{rGO} \mathrm{H}_{2} \mathrm{SO}_{4} ; \mathrm{rGO} \mathrm{DI} \mathrm{H}_{2} \mathrm{SO}_{4}$ ), as there is no significant change in the current response in $\mathrm{O}_{2^{-}}, \mathrm{N}_{2^{-}}$or airsaturated $0.1 \mathrm{M} \mathrm{KOH} \mathrm{(Fig.} \mathrm{11).} \mathrm{The} \mathrm{dissolved} \mathrm{gas} \mathrm{content} \mathrm{for}$ this air-saturated electrolyte is that which would exist when the $0.1 \mathrm{M} \mathrm{KOH}$ solution is stored in the ambient laboratory environment.

The pseudocapacitive behaviour for the materials in Fig. 12 is a departure from a typical rectangular CV scan of a purely
Fig. 12 Cyclic voltammograms highlighting the effect of varied scan rates on the measured current density from graphene oxide reduced hydrothermally at $190^{\circ} \mathrm{C}$ for 12 hours under high pressure $(180-190 \mathrm{psi})$ in distilled water (rGO DI $\mathrm{H}_{2} \mathrm{O}$ ), $0.1 \mathrm{M}$ sulphuric acid ( $\mathrm{rGO} \mathrm{H}_{2} \mathrm{SO}_{4}$ ) and $0.33 \mathrm{M}$ hydrazine $\left(\mathrm{rGO} \mathrm{N}_{2} \mathrm{H}_{4}\right)$, respectively. Graphene oxide and graphite are also shown for comparison purposes.

Measurements were taken in airsaturated $0.1 \mathrm{M} \mathrm{KOH}$ using a GCE disc substrate $\left(0.0706 \mathrm{~cm}^{2}\right)$ for the particulate coatings
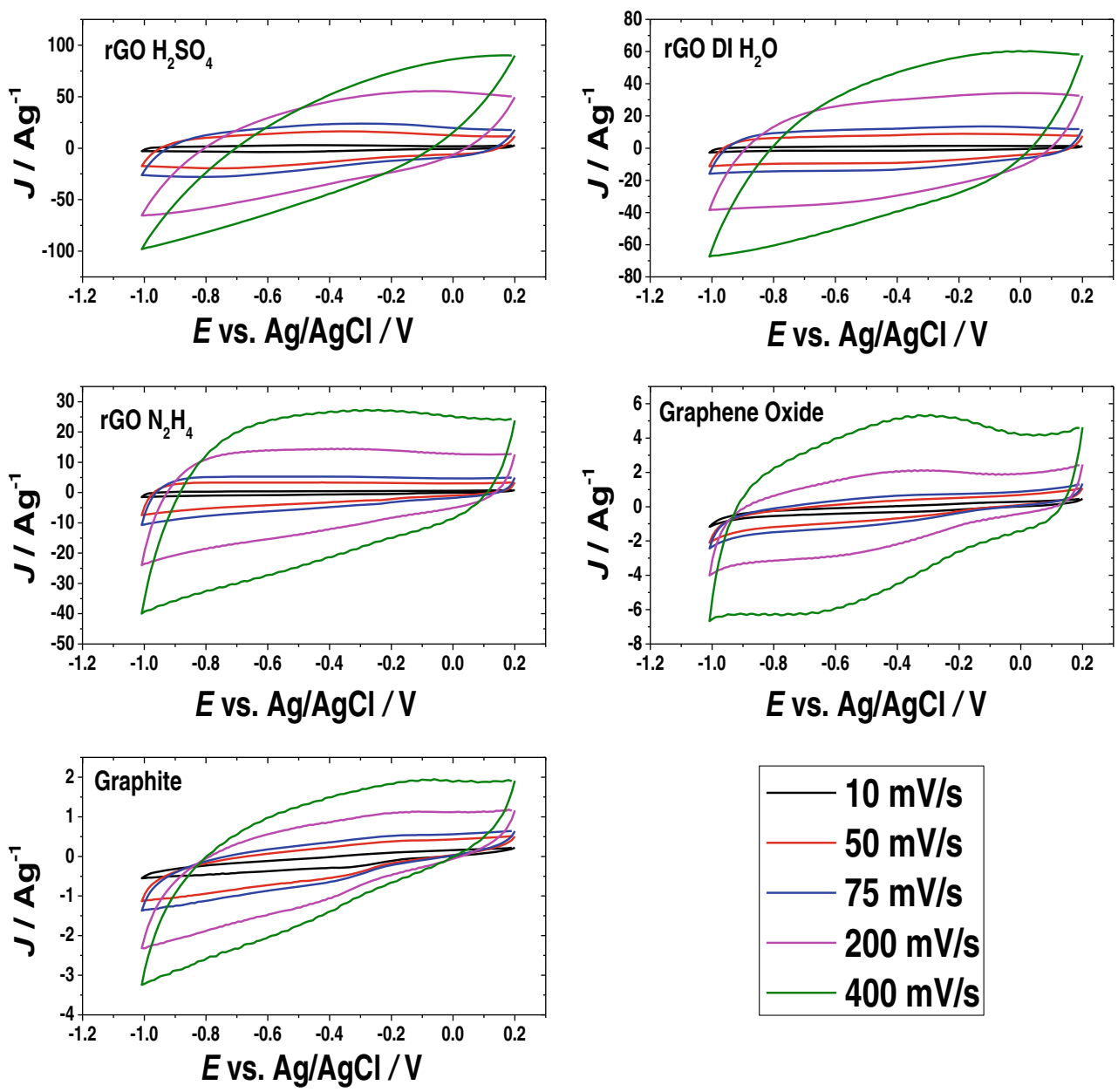
non-faradaic capacitive response. CV measurements in Fig. 12 indicate a varied current magnitude, which is influenced by faradaic processes along with the underlying nonfaradaic behaviour [14]. Nitrogen incorporation (3.9 at.\%) after GO reduction in $0.33 \mathrm{M}$ hydrazine (Table 4; Fig. 7) is a contributing factor to the increased capacitance present at the surface of the $\mathrm{rGO} \mathrm{N}_{2} \mathrm{H}_{4}$ sample. Pyridinic-N and pyrrolic-N incorporation are the most beneficial types of nitrogen bonding for promotion of pseudocapacitive current, which is due to the higher electronic charge density inferred [120-124]. The incorporated nitrogen modifies the electronic configuration, rendering the surface of the rGO $\mathrm{N}_{2} \mathrm{H}_{4}$ sample more susceptible to ion adsorption, increasing the specific capacitance [125]. Also, the oxygen content of the $\mathrm{rGO} \mathrm{N}_{2} \mathrm{H}_{4}$ sample (O 1s 5.12 at.\%) of the current study (Table 4) is lower in comparison to the rGO DI $\mathrm{H}_{2} \mathrm{O}$ and $\mathrm{rGO} \mathrm{H}_{2} \mathrm{SO}_{4}$ samples promoting a higher conductivity, thus enhancing the capacitive response [126, 127].

The capacitance response of the $\mathrm{rGO} \mathrm{H}_{2} \mathrm{SO}_{4}$ sample can be attributed to the high level of C-C $s p^{2}$ lattice restoration after reduction of the graphene oxide $[35,128]$, indicated by the highest increase in the $I_{D} / I_{G}$ ratio (1.43) during Raman analysis (Figs. 2 and $\mathrm{S} 1$; Table 1). The $\mathrm{C}-\mathrm{C} s p^{2}$ bonding restoration along with a decrease in oxygen content contribute to the promotion of a pseudocapacitive behaviour [35, 127, 128]. Sulphur also assists in increasing the capacitive response of graphene preparations $[129,130]$. The $\mathrm{rGO}_{2} \mathrm{SO}_{4}$ sample indicates a high level of defects at the surface of the $\mathrm{GO}$ after
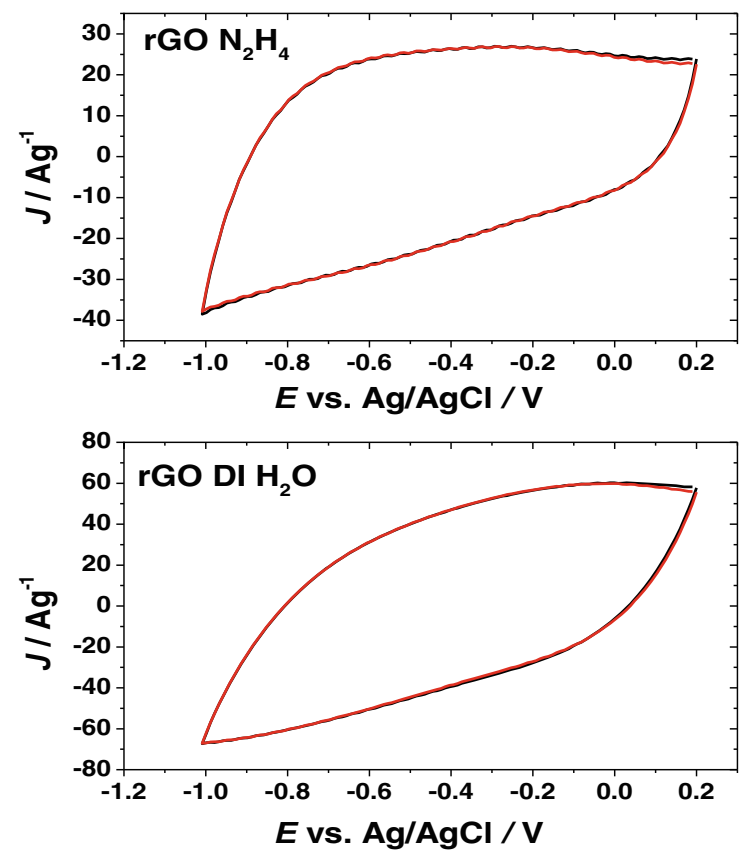

Fig. 13 Cyclic voltammograms of $0.424 \mathrm{mg} \mathrm{cm}^{-2}$ material coatings of graphene oxide reduced in distilled water $\left(\mathrm{rGO} \mathrm{DI} \mathrm{H}_{2} \mathrm{O}\right), 0.1 \mathrm{M}$ sulphuric acid $\left(\mathrm{rGO} \mathrm{H}_{2} \mathrm{SO}_{4}\right)$ and $0.33 \mathrm{M}$ hydrazine $\left(\mathrm{rGO} \mathrm{N}_{2} \mathrm{H}_{4}\right)$, respectively. The first (black) and the last (red) CV scans are displayed from a 10,000 reduction in $0.1 \mathrm{M}$ sulphuric acid, as highlighted by the highest $I_{D} / I_{G}$ ratio from Raman data (1.43) (Table 1) [33]. The carbon lattice defects can contribute to the incorporation of sulphur present in the $\mathrm{rGO}_{2} \mathrm{SO}_{4}$ sample [87]. These aspects of the $\mathrm{rGO}_{2} \mathrm{SO}_{4}$ sample promote the pseudocapacitive current response observed (Figs. 11 and 12). The rGO DI $\mathrm{H}_{2} \mathrm{O}$ sample has an enhanced pseudocapacitive response as a result of the decrease in the oxygen content (O 1s 14.47 at.\%) (Table 4), while a dramatic decrease in oxygen content (O 1s 5.12 at.\%) appears to contribute to the promotion of the prominent pseudocapacitive behaviour of the $\mathrm{rGO} \mathrm{N}_{2} \mathrm{H}_{4}$ sample (Figs. 11 and 12; Table 4).

The $\mathrm{pH}$ of the graphene oxide suspension during reduction has been noted to influence the topology of the resultant graphene sheets [32]. The more acidic the hydrothermal suspension during graphene oxide reduction, the more variation in the structure [32], while an alkaline solution allows the formation of graphene sheets with a lower amount of surface defects indicated [32]. This correlates with the low defects suggested by the low $I_{D} / I_{G}$ ratio value from the $\mathrm{rGO} \mathrm{N} \mathrm{N}_{2} \mathrm{H}_{4}$ sample $\left(I_{D} / I_{G}=1.00\right)$, derived from treatment in an alkaline solution of $0.33 \mathrm{M}$ hydrazine $(\mathrm{pH}$ $\sim 10$ ). While the more acidic hydrothermal treatment of the GO suspension $(0.1 \mathrm{M}$ sulphuric acid $(\mathrm{pH} \sim 1))$, provides indications of a high level of surface defects, as shown by Raman analysis (Figs. 2 and S1; Table 1).

Figure 13 highlights the change of the current response between the beginning (scan 1) and conclusion (scan 10,000) of a continuous repetitive CV analysis. A
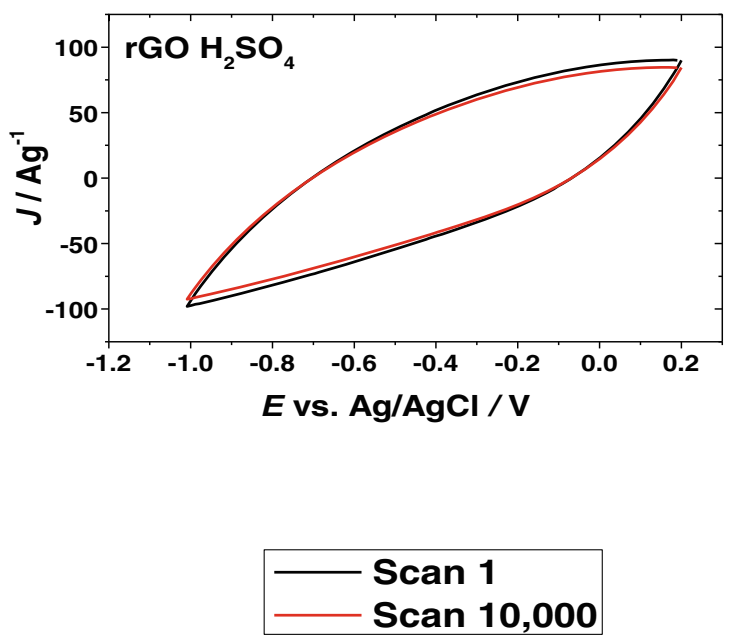

continuous repetitive $\mathrm{CV}$ analysis. Scan rate employed is $400 \mathrm{mV} \mathrm{s}^{-1}$. $\mathrm{CV}$ measured in air-saturated $0.1 \mathrm{M} \mathrm{KOH}$. The GCE disc used for analysis has a working area of $0.0706 \mathrm{~cm}^{2}$ 
highly stable current is indicated for all the rGO samples analysed in the present study, confirming the validity and stability of the pseudocapacitive behaviour observed (Fig. 13).

Elaboration on the dynamics at the surface of the rGO coatings during electrochemical analysis

EIS is ideally placed to analyse the capacitive response observed in the rGO samples under investigation (Fig. 14). EIS measurements of the graphene oxide before reduction and the graphene oxide reduced in distilled water $\left(\mathrm{rGO}\right.$ DI $\mathrm{H}_{2} \mathrm{O}$ ) and $0.1 \mathrm{M}$ sulphuric acid ( $\mathrm{rGO} \mathrm{H}_{2} \mathrm{SO}_{4}$ ), respectively, indicate that the overall impedance modulus (IZI) decreases in a sequential manner within the frequency range of $10^{-2}$ to $10^{0} \mathrm{~Hz}$ (Fig. 14). The rGO DI $\mathrm{H}_{2} \mathrm{O}$ sample has a higher impedance modulus than the rGO $\mathrm{H}_{2} \mathrm{SO}_{4}$ sample, while the graphene oxide provides the highest overall impedance in the low frequency range of the EIS analysis (Fig. 14).

The lower the cathodic pseudocapacitive current measured, the higher the impedance detected between $10^{\circ}$ and $10^{-2} \mathrm{~Hz}$ at the surface of the electrode coating material. This is confirmed when considering the current response from $\mathrm{CV}$ analysis at $-0.1 \mathrm{~V}$ for the graphene oxide, rGO DI $\mathrm{H}_{2} \mathrm{O}$ and $\mathrm{rGO} \mathrm{H}_{2} \mathrm{SO}_{4}$ samples (Figs. S5a and 14). This phenomenon is further confirmed when considering the impedance response from the same sample preparation at different applied potentials (Fig. S6). At $-0.16 \mathrm{~V}$, the cathodic current is higher in comparison to the cathodic current response obtained at $-0.1 \mathrm{~V}$, as illustrated in $\mathrm{CV}$ analysis displayed in the supporting information (Fig. S5b-d). This clarifies that it is the

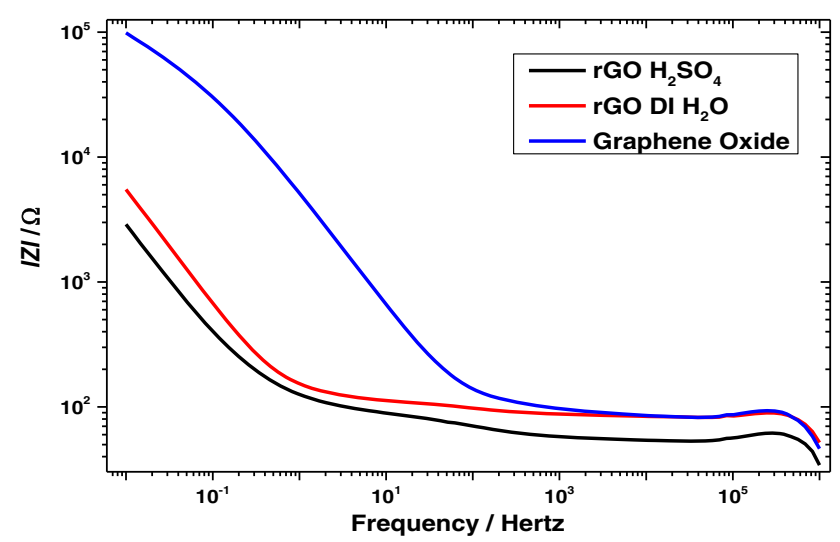

Fig. 14 Bode plots highlighting the change in the impedance modulus (IZI) from graphene oxide before and after reduction at $190{ }^{\circ} \mathrm{C}$ for 12 hours at $180 \mathrm{psi}$ in distilled water and $0.1 \mathrm{M}$ sulphuric acid suspension, respectively. The impedance spectra were measured in $\mathrm{O}_{2}$-saturated $0.1 \mathrm{M} \mathrm{KOH}$ at a fixed potential of $-0.1 \mathrm{~V}$ with a superimposed alternating potential of $10 \mathrm{mV}$ oscillation applied at a frequency range of $10^{6}$ to $10^{-2} \mathrm{~Hz}$. GCE disc used for analysis has a working area of $0.0706 \mathrm{~cm}^{2}$ change in the current response provided by the faradaic processes at the electrode surface which influences the change in the impedance modulus at -0.16 and $-0.1 \mathrm{~V}$. If a purely capacitive behaviour existed, the current response would be relatively unchanged between -0.16 and $-0.1 \mathrm{~V}$ during CV analysis. This is not the case for this study, due to a faradaic reaction providing a pseudocapacitive response which changes the detected current as the voltage changes during CV analysis (Fig. S5). For the graphene oxide sample, it is speculated that the charge transfer resistance from surface electrochemical reactions is reduced considerably in comparison to the rGO samples analysed, causing the significant increase in the impedance response (Figs. 14 and S5a).

\section{Conclusions}

LSV analyses show an oxygen reduction onset potential which is constant for all $\mathrm{rGO}$ samples ( $\mathrm{rGO} \mathrm{DI} \mathrm{H}_{2} \mathrm{O}, \mathrm{rGO} \mathrm{H}_{2} \mathrm{SO}_{4}$ and rGO $\left.\mathrm{N}_{2} \mathrm{H}_{4}\right)$ measured in this study $(-0.12 \mathrm{~V})$. The ORR cathodic current response increases significantly for the $\mathrm{rGO}$ $\mathrm{H}_{2} \mathrm{SO}_{4}$ sample, accompanied by an electron transfer efficiency that was higher than the rGO DI $\mathrm{H}_{2} \mathrm{O}$ and $\mathrm{rGO} \mathrm{N}_{2} \mathrm{H}_{4}$ samples. Hydrothermal reduction of GO in distilled water is noted to significantly improve the ORR catalysis from that observed for the graphite and graphene oxide starting materials. The oxidation of graphite (O $1 \mathrm{~s}=3.03$ at. $\%)$ to graphene oxide $(\mathrm{O} 1 \mathrm{~s}=35.63$ at.\%) is confirmed by the significant increase in the oxygen content detected by XPS analysis. Subsequent reduction of GO in distilled water $(\mathrm{O} 1 \mathrm{~s}$ of $\mathrm{rGO}$ DI $\mathrm{H}_{2} \mathrm{O}=14.47$ at.\%), $0.1 \mathrm{M}$ sulphuric acid (O 1s of rGO $\mathrm{H}_{2} \mathrm{SO}_{4}=16.09$ at. $\%$ ) and $0.33 \mathrm{M}$ hydrazine (O 1s of rGO $\mathrm{N}_{2} \mathrm{H}_{4}=5.12$ at.\%), respectively, is confirmed by the clear decrease in the oxygen content after hydrothermal treatment. The enhanced ORR from the $\mathrm{rGO}_{2} \mathrm{SO}_{4}$ sample is indicated to be assisted by the incorporation of sulphur into the carbon lattice structure, together with a significant decrease in oxygen content after GO reduction. An increase in the specific surface area, together with an indicated enhancement of surface porosity, after reduction of GO in $0.1 \mathrm{M}$ sulphuric acid, is also considered to contribute to the increased electrochemical behaviour of $\mathrm{rGO} \mathrm{H}_{2} \mathrm{SO}_{4}$ sample. There is similarity between the ORR current observed for the rGO $\mathrm{N}_{2} \mathrm{H}_{4}$ sample and that provided by the rGO $\mathrm{H}_{2} \mathrm{SO}_{4}$ sample. The enhancement of ORR in the rGO $\mathrm{N}_{2} \mathrm{H}_{4}$ sample is speculated to be as a result of the significant level of pyrrolic nitrogen bonding after doping of the rGO during GO reduction in $0.33 \mathrm{M}$ hydrazine, together with the decrease in the oxygen content, which may allow an increase in conductivity.

The smallest particle fractions of the $\mathrm{rGO}$ DI $\mathrm{H}_{2} \mathrm{O}$ and $\mathrm{rGO}$ $\mathrm{H}_{2} \mathrm{SO}_{4}$ samples contains few- to single-layer graphene 
particles as indicated by AFM analysis. The high increase of the $I_{D} / I_{G}$ ratio for the $\mathrm{rGO} \mathrm{H}_{2} \mathrm{SO}_{4}$ sample indicates an increase in the point defects that may act as ORR active sites resulting in an enhancement of catalysis. These defects are indicated to increase as a result of the decrease of the domain size in the carbon lattices. The minute amount of sulphur incorporation may also contribute to the abundance of carbon lattice defects.

A significant difference in charging current is indicated before ORR onset in LSV analysis of the rGO samples produced. This shows a varied capacitive effect at the rGO surface, resulting from a change in the medium used during hydrothermal GO reduction. The developed rGO samples provide a prominent pseudocapacitive behaviour under the diffusion-dependent conditions of $\mathrm{CV}$ analysis. The pseudocapacitive current response of the $\mathrm{rGO}$ DI $\mathrm{H}_{2} \mathrm{O}$ and $\mathrm{rGO} \mathrm{H}_{2} \mathrm{SO}_{4}$ samples is only slightly affected by the change of the dissolved oxygen concentration in the electrolyte. This shows a slight contribution to the current from oxygen reduction during $\mathrm{CV}$ analysis, but the dominant reaction appears to be a redox system. This indicates the involvement of carbonyl groups, such as quinones, in a redox reaction at the surface of the rGO particulates. The redox cycling of the quinone derivatives could cause the attenuated and broad reduction and oxidation peaks observed during cyclic voltammetry analysis. The reliability of the pseudocapacitive behaviour of all the rGO samples is observed with a stable pseudocapacitive current over a continuous $10,000 \mathrm{CV}$ scan assessment. The impedance is highest for the graphene oxide electrode preparation. As the overall pseudocapacitive current increases, the impedance decreases. GO reduction in hydrazine incorporates nitrogen into the carbon lattice (3.9 at.\%), which is indicated to assist in increasing the specific capacitance calculated.

The proposed facile method of rGO production allows a potentially cost effective and scalable avenue towards fuel cell catalyst material which could contribute to making this technology more widely available. With similarity between the GO reduced in sulphuric acid with that of rGO produced in hydrazine, the possible redundancy of toxic chemical-based GO reduction methods is also suggested. The pseudocapacitive behaviour for the developed rGO samples of this study indicates potential for future applications in the area of electrical power storage devices.

Acknowledgments The authors wish to acknowledge the financial support of the Department of Employment and Learning, Northern Ireland, during the completion of this study. Assistance with access to freeze-drying facilities from Dr. Mukhtar Ahmed is graciously acknowledged. Sincere gratitude is extended to Mrs. Grace Hayes for her sound support and to Mr. William Bartolome Hayes for important motivation.

\section{References}

1. Kim J, Cote LJ, Huang J (2012) Acc Chem Res 45:1356-1364

2. Buchsteiner A, Lerf A, Pieper J (2006) J Phys Chem B 110:2232822338

3. Schniepp H, Li J, McAllister M, Sai H, Herrera-Alonso M, Adamson D, Prudhomme RK, Car R, Saville DA, Aksay IA (2006) J Phys Chem B 110:8535-8539

4. Szabó T, Berkesi O, Forgó P, Josepovits K, Sanakis Y, Petridis D, Dékány I (2006) Chem Mater 18:2740-2749

5. Hontoria-Lucas C, Lopez-Peinado AJ, Lopez-Gonzalez JD, RojasCervantes ML, Martin-Aranda RM (1995) Carbon 33:1585-1592

6. Mattevi C, Eda G, Agnoli S, Miller S, Mkhoyan K, Celik O, Mastrogiovanni D, Granozzi G, Garfunkel E, Chhowalla M (2009) Adv Funct Mater 19:2577-2583

7. Sutar DS, Narayanam PK, Singh G, Botcha VD, Talwar SS, Srinivasa RS, Major SS (2012) Thin Solid Films 520:5991-5996

8. Park S, An SJ, Potts J, Velamakanni A, Murali S, Ruoff R (2011) Carbon 49:3019-3023

9. Shin H, Kim K, Benayad A, Yoon S, Park H, Jung I, Jin M, Jeong H, Kim J, Choi J, Lee Y (2009) Adv Funct Mater 19:1987-1992

10. Su CY, Xu YP, Zhang WJ, Zhao JW, Liu AP, Tang XH, Tsai CH, Huang YZ, Li LJ (2010) ACS Nano 4:5285-5292

11. Stankovich S, Dikin DA, Piner RD, Kohlhaas KA, Kleinhammes A, Jia Y, Wu Y, Nguyen ST, Ruoff RS (2007) Carbon 45:1558-1565

12. Chen H, Müller MB, Gilmore KJ, Wallace GG, Li D (2008) Adv Mater 20:3557-3561

13. Si Y, Samulski ET (2008) Nano Lett 8:1679-1682

14. Perera SD, Mariano RG, Nijem N, Chabal Y, Ferraris JP, Balkus KJ Jr (2012) J Power Sources 215:1-10

15. Chua CK, Pumera M (2014) Chem Soc Rev 43:291-312

16. Bourlinos AB, Gournis D, Petridis D, Szabó T, Szeri A, Dékány I (2003) Langmuir 19:6050-6055

17. Wang G, Yang J, Park J, Gou X, Wang B, Liu H, Yao J (2008) J Phys Chem C 112:8192-8195

18. Cote LJ, Cruz-Silva R, Huang JX (2009) J Am Chem Soc 131: $11027-11032$

19. Zhang Y, Guo L, Wei S, He Y, Xia H, Chen Q, Sun H-B, Xiao F-S (2010) NanoToday 5:15-20

20. Mao S, Pu H, Chen J (2012) RSC Adv 2:2643-2662

21. Hassan H, Abdelsayed V, Khder A, AbouZeid K, Terner J, El-Shall M, Al-Resayes SI, El-Azhary AA (2009) J Mater Chem 19:38323837

22. Wei ZQ, Wang DB, Kim S, Kim SY, Hu YK, Yakes MK, Laracuente AR, Dai ZT, Marder SR, Berger C, King WP, de Heer WA, Sheehan PE, Riedo E (2010) Science 328:1373-1376

23. Zhu YW, Stoller MD, Cai WW, Velamakanni A, Piner RD, Chen D, Ruoff RS (2010) ACS Nano 4:1227-1233

24. Baraket M, Walton SG, Wei Z, Lock EH, Robinson JT, Sheehan P (2010) Carbon 48:3382-3390

25. Chen WF, Yan LF, Bangal PR (2010) Carbon 48:1146-1152

26. Sokolov DA, Shepperd KR, Orlando TM (2010) J Phys Chem Lett 1:2633-2636

27. Yang D, Velamakanni A, Bozoklu G, Park S, Stoller M, Piner RD, Stankovich S, Jung I, Field DA, Ventrice CA, Ruoff RS (2009) Carbon 47:145-152

28. Yao PP, Chen PL, Jiang L, Zhao HP, Zhu HF, Zhou D, Hu WP, Han BH, Liu MH (2010) Adv Mater 22:5008-5012

29. Zhu W, Murali S, Stoller MD, Velamakanni A, Piner RD, Ruoff RS (2010) Carbon 48:2118-2122

30. McAllister M, Li J, Adamson D, Schniepp H, Abdala A, Liu J, Herrera-Alonso M, Milius DL, Car R, Prudhomme RK, Aksay IA (2007) Chem Mater 19:4396-4404

31. Min K, Han TH, Kim J, Jung J, Jung C, Hong SM, Koo CM (2012) J Colloid Interface Sci 383:36-42 
32. Bosch-Navarro C, Coronado E, Martí-Gastaldo C, Sánchez-Royo JF, Gómez MG (2012) Nanoscale 4:3977-3982

33. Zhou Y, Bao Q, Tang LAL, Zhong Y, Loh KP (2009) Chem Mater 21:2950-2956

34. Gao W, Alemany L, Ci L, Ajayan P (2009) Nat Chem 1:403-408

35. Tien HN, Luan VH, Lee TK, Kong B-S, Chung JS, Kim EJ, Hur SH (2012) Chem Eng J 211-212:97-103

36. Lin L, Zhang S (2012) J Mater Chem 22:14385-14393

37. Fan L-Z, Liu J-L, Ud-Din R, Yan X, Qu X (2012) Carbon 50:37243730

38. Jiaoxing X (2013) Chemsuschem 6:493-499

39. Lee KR, Lee KU, Lee JW, Ahn BT, Woo SI (2010) Electrochem Commun 12:1052-1055

40. Huang C, Li C, Shi G (2012) Energy Environ Sci 5:8848-8868

41. Hummers W, Offeman R (1958) J Am Chem Soc 80:13391339

42. Kong HX (2013) Curr Opin Solid State Mater Sci 17:31-37

43. Eigler S, Grimm S, Hirsch A (2014) Chem Eur J 20:984-989

44. Liu C, Yu Z, Neff D, Zhamu A, Jang BZ (2010) Nano Lett 10:48634868

45. Yan J, Liu JP, Fan ZJ, Wei T, Zhang LJ (2012) Carbon 50:21792188

46. Gomez-Navarro C, Weitz RT, Bittner AM, Scolari M, Mews A, Burghard M, Kern K (2007) Nano Lett 7:3499-3503

47. Lomeda JR, Doyle CD, Kosynkin DV, Hwang W-F, Tour JM (2008) J Am Chem Soc 130:16201-16206

48. Gokus T, Nair RR, Bonetti A, Bohmler M, Lombardo A, Novoselov KS, Geim AK, Ferrari AC, Hartschuh A (2009) ACS Nano 3:39633968

49. Trusovas R, Ratautas K, Raciukaitis G, Barkauskas J, Stankeviciene I, Niaura G, Mazeikiene R (2013) Carbon 52:574-582

50. Graf D, Molitor F, Ensslin K, Stampfer C, Jungen A, Hierold C, Wirtz L (2007) Eur Phys J Spec Top 148:171-176

51. Rohrl J, Hundhausen M, Emtsev K, Seyller T, Graupner R, Ley L (2008) Appl Phys Lett 92:201918-201921

52. Ferrari AC (2007) Solid State Commun 143:47-57

53. Ferrari AC, Meyer JC, Scardaci V, Casiraghi C, Lazzeri M, Mauri F, Pisanec S, Jiang D, Novoselov KS, Roth S, Geim AK (2006) Phys Rev Lett 97:187401

54. Boutchich M, Jaffré A, Alamarguy D, Alvarez J, Barras A, Tanizawa Y, Tero R, Okada H, Thu TV, Kleider JP, Sandhu A (2013) J Phys Conf Ser 433:012001

55. Ganguly A, Sharma S, Papakonstantinou P, Hamilton J (2011) J Phys Chem C 115:17009-17019

56. Fan ZJ, Wang K, Wei T, Yan J, Song LP, Shao B (2010) Carbon 48: $1686-1689$

57. Li Y, Lv X, Lu J, Li J (2010) J Phys Chem C 114:21770-21774

58. He D, Kou Z, Xiong Y, Cheng K, Chen X, Pan M, Mu S (2014) Carbon 66:312-319

59. Wang W, Wang Z, Liu Y, Li N, Wang W, Gao J (2012) Mater Res Bull 47:2245-2251

60. Pham VH, Cuong TV, Hur SH, Oh E, Kim EJ, Shin EW, Chung JS (2011) J Mater Chem 21:3371-3377

61. Park S, An J, Jung I, Piner RD, An SJ, Li X, Velamakanni A, Ruoff RS (2009) Nano Lett 9:1593-1597

62. Lerf A, Buchsteiner A, Pieper J, Schottl S, Dekany I, Szabo T, Boehm HP (2006) J Phys Chem Solids 67:1106-1110

63. Liu C, Hu G, Gao H (2012) J Supercrit Fluids 63:99-104

64. Antolini E (2012) Appl Catal B Environ 123-124:52-68

65. Ban FY, Majid SR, Huang NM, Lim HN (2012) Int J Electrochem Sci 7:4345-4351

66. Hsieh C-T, Hsu S-M, Lin J-Y, Teng H (2011) J Phys Chem C 115: 12367-12374

67. Liang J, Jiao Y, Jaroniec M, Qiao SZ (2012) Angew Chem Int Ed $51: 11496-11500$

68. Wan S, Wang L, Xue Q (2010) Electrochem Commun 12:61-65
69. Fan X, Peng W, Li Y, Li X, Wang S, Zhang G, Zhang F (2008) Adv Mater 20:4490-4493

70. Guo H-L, Peng S, Kang X, Ning S-K (2013) J Mater Chem 1:22482255

71. Pham VH, Pham HD, Dang TT, Hur SH, Kim EJ, Kong BS, Kim S, Chung JS (2012) J Mater Chem 22:10530-10536

72. Vesel A, Mozetic M (2009) J Phys Conf Ser 162:012015

73. Choi CH, Park SH, Woo SI (2011) Green Chem 13:406-412

74. Seredych M, Tamashausky AV, Bandosz TJ (2010) Adv Funct Mater 20:1670-1679

75. Ellis AV, Al-deen A, Dalal H, Andersson GG (2013) J Phys Chem C 117:21312-21319

76. Chen W, Yan L, Bangal PR (2010) J Phys Chem C 114:1988519890

77. Zhao G, Jiang L, He Y, Li J, Dong H, Wang X, Hu W (2011) Adv Mater 23:3959-3963

78. Liu F, Sun J, Zhu L, Meng X, Qi C, Xiao F-S (2012) J Mater Chem 22:5495-5502

79. Novoselov K, Geim A, Morozov S, Jiang D, Zhang Y, Dubonos S, Grigorieva IV, Firsov AA (2004) Science 306:666-669

80. Wu D, Zhang F, Liang H, Feng X (2012) Chem Soc Rev 41:61606177

81. Gao X, Jang J, Nagase S (2010) J Phys Chem C 114:832-842

82. Zalan Z, Lazar L, Fulop F (2005) Curr Org Chem 9:357-376

83. Bard AJ, Faulkner LR (2001) Electrochemical methods fundamentals and applications, 2nd edn. Wiley, Hoboken

84. Yang H-H, McCreery RL (2000) J Electrochem Soc 147:34203428

85. Song C, Zhang J (2008) In: Zhang J (ed) PEM fuel cell electrocatalysts and catalyst layers, vol 12. Springer, Vancouver

86. Wu J, Yang H (2013) Acc Chem Res 46:1848-1857

87. Yang Z, Yao Z, Li G, Fang G, Nie H, Liu Z, Zhou X, Chen X, Huang S (2012) ACS Nano 6:205-211

88. Wohlgemuth S-A, White RJ, Willinger M-G, Titirici M-M, Antonietti M (2012) Green Chem 14:1515-1523

89. Park J-E, Jang YJ, Kim YJ, Song MS, Yoon S, Kim DH, Kim SJ (2014) Phys Chem Chem Phys 16:103-109

90. Seredych M, Bandosz TJ (2014) Carbon 66:227-233

91. Slater JC (1964) J Chem Phys 41:3199

92. Lu Z-J, Bao S-J, Gou Y-T, Cai C-J, Ji C-C, Xu M-W, Song J, Wang R (2013) RSC Adv 3:3990-3995

93. Wu J, Wang Y, Zhang D (2011) Adv Mater Res 197-198:667-671

94. Huang D, Zhang B, Zhang Y, Zhaan F, Xu X, Shen Y, Wang M (2013) J Mater Chem A 1:1415-1420

95. Xu S, Yong L, Wu P (2013) ACS Appl Mater Interfaces 5:654-662

96. Fu X, Liu Y, Cao X, Jin J, Liu Q, Zhang J (2013) Appl Catal B Environ 130-131:143-151

97. He D, Jiang Y, Lv H, Pan M, Mu S (2013) Appl Catal B Environ 132-133:379-388

98. Koutecky J, Levich VG (1958) Zh Fiz Khim 32:1565-1575

99. Koutecky J, Levich VG (1957) Dokl Akad Nauk SSSR 117:441444

100. Masa J, Batchelor-McAuley C, Schuhmann W, Compton RG (2014) Nano Res 7:71-78

101. Yang Z, Nie H, Chen X, Chen X, Huang S (2013) J Power Sources 236:238-249

102. Yang S, Feng X, Wang X, Müllen K (2011) Angew Chem Int Ed 50:5339-5343

103. Zhou X, Yang Z, Nie H, Yao Z, Zhang L, Huang S (2011) J Power Sources 196:9970-9974

104. Yang Z, Zhou X, Nie H, Yao Z, Huang S (2011) ACS Appl Mater Interfaces 3:2601-2606

105. Brunauer S, Emmett PH, Teller E (1938) J Am Chem Soc 60:309-319

106. You S, Luzan SM, Szabó T, Talyzin AV (2013) Carbon 52:171-180

107. Farghali AA, Bahgat M, El Rouby WMA, Khedr MH (2013) J Alloys Compd 555:193-200 
108. Mishra AK, Ramaprabhu S (2011) Desalination 282:39-45

109. Jiang Y, Chen D, Song J, Jiao Z, Ma Q, Zhang H, Cheng L, Zhao B, Chu Y (2013) Electrochim Acta 91:173-178

110. Radich JG, Kamat PV (2012) ACS Catal 2:807-816

111. Li Y, van Zijll M, Chiang S, Pan N (2011) J Power Sources 196: 6003-6006

112. Guin PS, Das S, Mandal PC (2008) Int J Electrochem Sci 3:10161028

113. Guin PS, Das S, Mandal PC (2010) J Phys Org Chem 23:477-482

114. Gill R, Stonehill HI (1952) J Chem Soc:1845-1857

115. Furman NH, Stone KG (1948) J Am Chem Soc 70:3055-3061

116. Nurmi JT, Tratnyek PG (2002) Environ Sci Technol 36:617-624

117. Sarapuu A, Helstein K, Vaik K, Schiffrin DJ, Tammeveski K (2010) Electrochim Acta 55:6376-6382

118. Sarapuu A, Vaik K, Schiffrin DJ, Tammeveski K (2003) J Electroanal Chem 541:23-29

119. Li Q, Batchelor-McAuley C, Lawrence NS, Hartshorne RS, Compton RG (2011) Chem Phys Chem 12:1255-1257
120. Lee Y-H, Chang K-H, Hu C-C (2013) J Power Sources 227:300308

121. Frackowiak E (2007) Phys Chem Chem Phys 9:1774-1785

122. Hulicova-Jurcakova D, Kodama M, Shiraishi S, Hatori H, Zhu ZH, Lu GQ (2009) Adv Funct Mater 19:1800-1809

123. Lota G, Lota K, Frackowiak E (2007) Electrochem Commun 9: $1828-1832$

124. Jeong HM, Lee JW, Shin WH, Choi YJ, Shin HJ, Kang JK, Choi JW (2011) Nano Lett 11:2472-2477

125. Zhu ZH, Hatori H, Wang SB, Lu GQ (2005) J Phys Chem B 109: 16744-16749

126. Bai Y, Rakhi RB, Chen W, Alshareef HN (2013) J Power Sources 233:313-319

127. Luo Z, Zhu L, Huang Y, Tang H (2013) Synth Met 175:88-96

128. Deakin MR, Wightman RM (1986) J Electroanal Chem 206:167-177

129. Deyi Z (2013) J Mater Chem A 1:7584-7591

130. Huang J-Q, Liu X-F, Zhang Q, Chen C-M, Zhao M-Q, Zhang S-M, Zhu W, Qian W-Z, Wei F (2013) Nano Energy 2:314-321 